\title{
Multi-objective optimisation for battery electric vehicle powertrain topologies
}

\author{
Pongpun Othaganont ${ }^{1}$, Francis Assadian ${ }^{2}$ and Daniel J. Auger ${ }^{1}$ \\ ${ }^{1}$ Advanced Vehicle Engineering Centre, Cranfield University, United Kingdom \\ ${ }^{2}$ Mechanical and Aerospace Engineering, University of California, Davis, United \\ States
}

Corresponding author: Daniel J. Auger, Advanced Vehicle Engineering Centre, Cranfield University, U.K. Email: d.j.auger@cranfield.ac.uk

\begin{abstract}
Electric vehicles are becoming more popular in the market. To be competitive, manufacturers need to produce vehicles with low energy consumption, good range, and acceptable driving performance. These are dependent on the choice of components and the topology in which they are used. In a conventional gasoline vehicle, the powertrain topology is constrained to a few wellunderstood layouts: these typically comprise a single engine driving one or both
\end{abstract}


axles through a multi-ratio gearbox. With electric vehicles, there is more flexibility and the design space is relatively unexplored. In this paper, we explore several different topologies: we consider a traditional topology using a single electric motor driving a single axle with fixed gear ratio; a topology using separate motors for the front and rear axles, each with its own fixed gear ratio; a topology using in-wheel motors on a single axle; and a four-wheel-drive topology using in-wheel motors on both axes. Multi-objective optimisation techniques are used to find optimal component sizing for a given requirement set and to explore the trade-offs between energy consumption, powertrain cost and acceleration performance. The paper concludes with a discussion of the relative merits of the different topologies and their applicability to real-world passenger cars.

\section{Keywords}

Battery electric vehicles; multi-objective optimization; powertrain topologies 


\section{Nomenclature}

A vehicle drag area $\left(\mathrm{m}^{2}\right)$

BEV battery electric vehicle

$C_{\mathrm{d}} \quad$ drag coefficient (dimensionless)

$C_{\mathrm{r}} \quad$ coefficient of rolling resistance (dimensionless)

$E \quad$ energy required to complete a specified driving cycle (J)

EM electric machine

EV electric vehicle

$F_{\mathrm{w}} \quad$ driving force at wheels $(\mathrm{N})$

$f(x) \quad$ function of variable $x$ (units vary)

$g \quad$ acceleration due to gravity $\left(\mathrm{m} / \mathrm{s}^{2}\right)$

$G_{\mathrm{F}}, G_{\mathrm{R}} \quad$ front and rear gear ratios in double-axle vehicle (dimensionless)

HEV hybrid electric vehicle

HIL hardware-in-(the)-loop

ICE internal combustion engine

$I_{\mathrm{T}, \mathrm{bat}} \quad$ current out of battery terminals (A)

IWM-DA in-wheel motor, double (driven) axle

IWM-SA in-wheel motor, single (driven) axle

$J_{i}\left(X_{\mathrm{D}}\right) \quad$ objective (cost) function $i$ parameterized on decision variables $X_{\mathrm{D}}$ (units vary) 


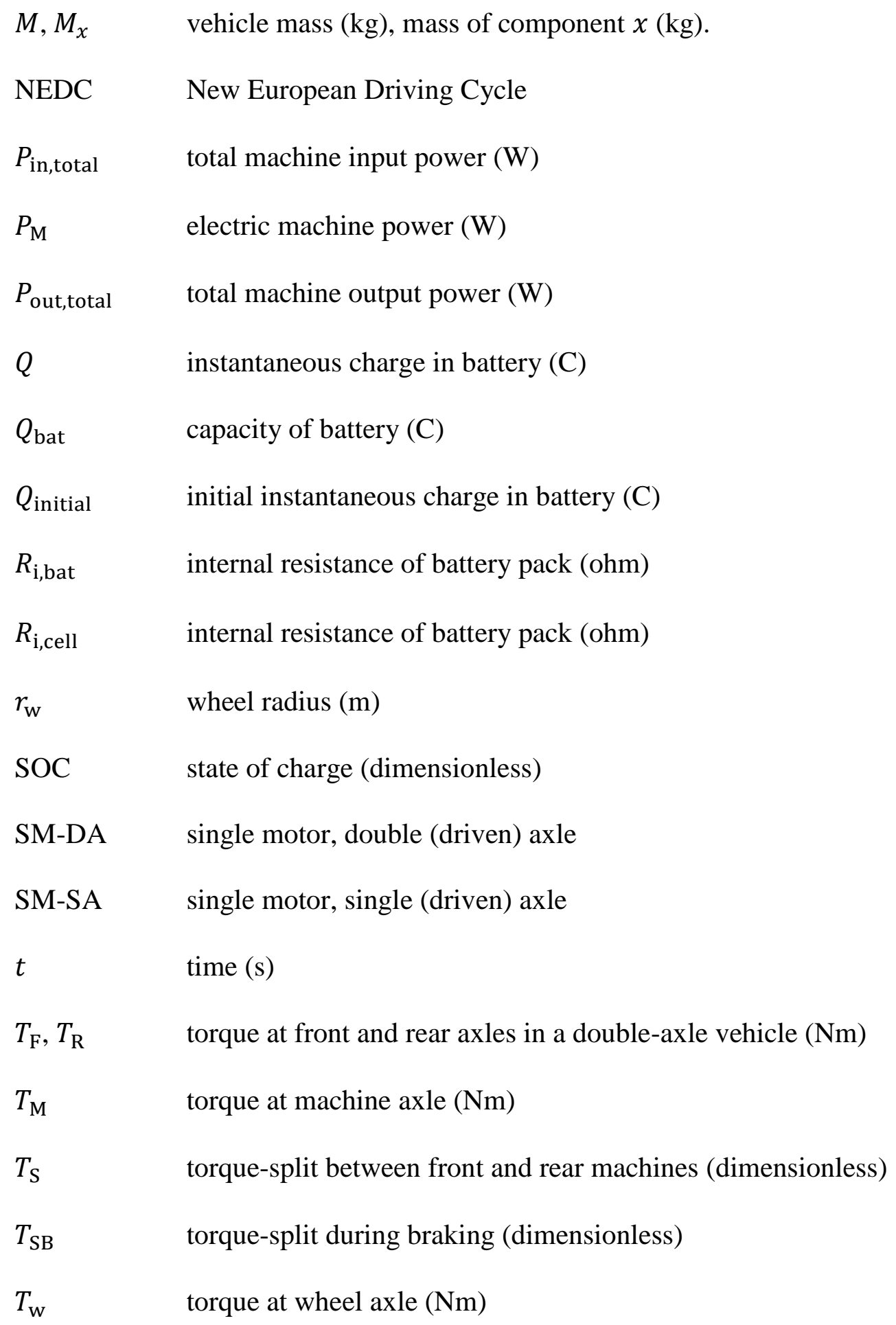




\begin{tabular}{|c|c|}
\hline$T_{100}$ & time taken to accelerate from rest to $100 \mathrm{~km} / \mathrm{h}(\mathrm{s})$ \\
\hline$V_{\mathrm{OCV}, \mathrm{bat}}$ & open-circuit voltage of a complete battery pack (V) \\
\hline$V_{\mathrm{OCV}, \text { cell }}$ & open-circuit voltage of a single cell $(\mathrm{V})$ \\
\hline$V_{\mathrm{T}, \mathrm{bat}}$ & voltage at battery terminals $(\mathrm{V})$ \\
\hline$v_{\text {vehicle }}$ & vehicle speed $(\mathrm{m} / \mathrm{s})$ \\
\hline$\eta_{\mathrm{F}}, \eta_{\mathrm{R}}$ & $\begin{array}{l}\text { efficiency of front and rear electric machines in double-axle vehicles } \\
(\mathrm{rad} / \mathrm{s})\end{array}$ \\
\hline$\eta_{G}$ & efficiency of gearbox (dimensionless) \\
\hline$\eta_{\mathrm{M}}$ & efficiency of electric machine (dimensionless) \\
\hline$\rho$ & density of air $\left(\mathrm{kg} / \mathrm{m}^{3}\right)$ \\
\hline$\phi_{\mathrm{F}}, \phi_{\mathrm{R}}$ & power rating of front and rear machines in a double-axle vehicle $(\mathrm{kW})$ \\
\hline$\phi_{\mathrm{M}}$ & power rating of electric machine $(\mathrm{kW})$ \\
\hline$\omega_{\mathrm{M}}$ & electric machine angular velocity $(\mathrm{rad} / \mathrm{s})$ \\
\hline$\omega_{\mathrm{M}, \text { front }}$ & front machine angular velocities in a double-axle vehicle (rad/s) \\
\hline$\omega_{\mathrm{M}, \mathrm{rear}}$ & rear machine angular velocities in a double-axle vehicle ( $\mathrm{rad} / \mathrm{s})$ \\
\hline$\omega_{\mathrm{w}}$ & wheel angular velocity (rad/s) \\
\hline
\end{tabular}




\section{Introduction}

In recent years environmental concerns have led many industries to focus on and adopt 'green' products and services. A good example of this is the passenger car, generally accepted as a major source of greenhouse gas emissions and air pollution. Governments have introduced legislation, taxation regimes and incentive schemes that force automotive companies to control vehicle emissions [1] and to encourage consumers to use efficient low-carbon vehicles. In the UK, for example, the government has subsidised $25 \%$ of the purchase price for ultra-low emission cars since early 2012 [2]. In response to all this, many automotive companies have attempted to reduce their fleet-averaged vehicle emissions by developing hybrid and electric vehicles.

Hybrid electric vehicles (HEVs) represent relatively mature technology, and are readily available and affordable at the present time. Hybrid vehicles use two or more energy sources, with the intent of exploiting the advantages of each. As the most widespread form of hybrid vehicle, HEVs combine the conventional internal combustion engine (ICE) with electric machines (EM). The key advantage of this type of vehicle is its greater fuel efficiency than that of the conventional ICE vehicle, brought about by the ability to 'downsize' the engine and operate it nearer to optimal conditions and - in some driving conditions - the ability to recover kinetic energy during braking. Assuming a diesel hybrid electric powertrain, one study has noted the potential of the shift in operating point brought about by downsizing to reduce overall fuel consumption by as 
much as $35 \%$, and the potential of regenerative braking to bring a further $8 \%$ reduction [3, Sec. 3.3.4]. There are many results in the literature. For example, one extended study showed that even without downsizing the engine, an operating point shift alone can produce a fuel savings of almost $30 \%$ on the New European Driving Cycle (NEDC) [4] and over $20 \%$ in experimental tests and real-world driving cycles [5]. Energy management systems continue to be a popular subject of research.

The HEV still derives its energy from fossil fuels and, it still some pollution while driving on city roads. Ideally, a passenger car would use pure electric energy and produce zero 'tailpipe' emissions. If a significant portion of the electricity can be generated from renewable sources, there is potential for further reductions in the true 'well to wheel' carbon emissions. One solution is the Battery Electric Vehicle (BEV). There are others - such as the plug-in hybrid electric vehicle and the fuel-cell electric vehicle - but the BEV is the fundamental base for these.

BEVs have been seen as a 'niche' product, but they are now establishing themselves in the mainstream market. Several automobile companies have included a BEV in their range: examples include the Nissan Leaf in the UK and US, the Tesla Roadster in the US, and the Mini E in Germany [6, 7]. BEVs are well-suited to everyday use since their battery capacity is sufficient for many consumers' day-to-day needs. Pearre et al [8] report that the majority of the US drivers covered a daily mileage of less than 100 miles, comparing well with the daily mileage capacity of the vehicles in the current market. 
The typical BEV in today's market differs from an ICE vehicle in that instead of having an engine and a fuel tank, the BEV has an electric machine and an electric energy storage unit $[9,10]$. However, much of the rest of the vehicle is similar to a conventional one: most BEVs still use a relatively conventional transmission system, including a clutch, a shaft drive, a gearbox and a differential. As with an ICE, the transmission affects overall efficiency and vehicle mass [10]. Electric machines have rather different characteristics from ICEs: the typical EM provides its maximum torque at low speed, compared to an ICE's 'peak' at a particular speed. Consequently, EVs can be operated with a single or double ratio transmissions [9] rather than the five-or-more speed transmission found in an ICE vehicle. The machines in today's market use varied machine types - the Tesla Roadster and the Mini E use single induction motors while the Nissan Leaf uses a permanent magnet synchronised motor - but all three use single-speed transmissions $[6,7]$. Apart from the number of gear ratios, the transmission in the typical BEV is remarkably similar to that of the conventional ICE vehicle.

With a BEV, the designer is not constrained to use the 'traditional' powertrain layout: there are several alternatives that would be impossible or impractical with an ICE vehicle, but are straightforward with an electric powertrain. Rather than using a differential, it is possible to use in an independent wheel drive, discussed in the literature [11] and implemented in prototype cars: the Lightning GT uses rear-wheel-drive from twin traction motors, each with a single speed reduction gearbox [12]. By using multiple 
machines, mechanical parts such as the differential can be eliminated and replaced by a 'virtual' differential effect from electrical control. It is also possible to transfer energy 'by wire' and locate electric machines close to their point of action, eliminating large mechanical transmission components: as well as reducing mass and adding flexibility, this can simplify mechanical layout and reduce space requirements. There are disadvantages: if one uses independent wheel drive, one needs to take great care to design the complex non-linear control laws needed for stability and safety. With a conventional vehicle, design of the differential and stability enhancements are to some extent 'decoupled' from overall torque delivery, but with independent wheel-drive, everything must be co-designed $[13,14]$. In addition, some possibilities - such as integrating motors within the wheel hubs themselves - can add to a vehicle's unsprung mass, which may cause problems with vehicle handling dynamics and vibration if not correctly dealt with [13].

It is clear that electric vehicles have an advantage over traditional ICE vehicles in that the designer has considerably more choice in terms of powertrain architecture [10]. Whereas a conventional vehicle must almost always be a 'single drive' configuration, a BEV can have a single drive motor, two independent drive motors with reducing gears, two independent motors with direct drive, or even in-wheel drive $[9,10]$. There is more opportunity for optimizing an architecture for a particular usage pattern. At the present time, the key weakness of the BEV is its limited range [6]. This may in time be solved, 
and efforts are currently underway into order to increase battery energy density [15], improve charging infrastructure [16], and reducing vehicle energy consumption. To get the most out of a BEV, it is important that powertrain layout and sizing is done in a way that is at least near-optimal in terms of minimising energy consumption, and there are established techniques for selecting appropriate vehicle parameters using suitable optimisation techniques [17].

There are several approaches to model-based powertrain optimization, and an excellent overview can be found in Guzzella and Sciaretta's text book on the subject [3]. Broadly speaking, an author must make two choices:

1. A decision must be made on the overall approach to modelling.

2. A decision must be made on the overall approach to optimization.

There are two broad approaches to modelling: the most 'conventional' is often described as 'forwards-facing' modelling. This is perhaps the most natural approach for engineers, taken by default. In forwards-facing modelling, the 'inputs' are forces and torques; the 'outputs' are the resulting motions.

In powertrain optimization, it is common to use models to predict the energy and fuel requirements associated with particular driving cycles. In these cases, the effective inputs are not forces, but motions. A forwards-facing model can be made to follow a driving cycle, but it is necessary to use some kind of feedback: a 'driver model' is es- 
sential. This approach can be very effective, but - as with all simulation problems involving feedback, it is slow in execution. Forwards-facing models can be made arbitrarily complex, and are very good for relatively slow modelling exercises - such as Hardware-In-Loop (HIL) testing or calibration, but they are harder to use for exercises in optimization where it is necessary either to run a model many times or to perform analytic mathematics on the model. In such cases, it may be preferable to use an alternative 'backwards-facing' modelling approach, based on quasi-static component models.

'Backwards-facing' models use motions as their 'inputs', and with the 'outputs' being the forces and torques required to produce such motions. Generally, fast-acting dynamics are hard to model, and are usually approximated with 'quasi-static' models [3, Sec. 4.1.2]. Models of this kind generally offer less fidelity than their 'forwards-facing' equivalents, but as they do not require driver models or feedback, they are fast in execution. Backwards models are used extensively in the literature, e.g. $[19,20]$ and there are also approaches that combine backwards models and forwards models, using backwards models for coarse-tuning and forwards models for fine-tuning [18, 21].

Having determined the approach to modelling, it is the necessary to determine an approach for optimization. Some studies, e.g. $[19,22]$, attempt to derive an analytic approximation for their objective functions, then solve these approximations. This can be used to optimize both component sizing and power-split strategy. This has the advantage of computational speed, though it is not always easy to derive the mathematics. 
For more complex problems, approaches based on parameter search methods are used. Popular algorithmic choices here are genetic algorithms, as used in [19] and [23].

The particular problem this paper addresses is that at present, while there are techniques for optimizing a particular vehicle configuration - or even for comparing two or more configurations - there is at present no complete solution to for the choice of the most appropriate BEV architecture for the three key objectives: energy efficiency, performance (acceleration) and affordability. This paper uses multi-objective optimization to explore the trade-offs between these targets for a chosen usage scenario. The approach taken will be to explore the trade-offs between pairs of objectives, ensuring that the 'best possible' powertrain configurations are chosen through the use of optimization. The result will be a set of guidelines showing how the conflicting objectives interact, and indicating the best topology to choose in order to meet any single objective or any pair.

This paper will start by presenting the different BEV topologies considered. It will then describe the way in which the vehicle and components were modelled and the multi-objective optimization used. It will then show the results of obtained and give guidelines on topology selection. 


\section{BEV powertrain topologies}

There are many possible electric vehicle topologies. These will briefly be discussed, and a subset will be considered for more detailed analysis. (The rationale for choosing this subset will also be described.)

\subsection{Single electric machine}

There are two possible technologies for a single-machine vehicle: a traditional powertrain formed by adapting a conventional ICE layout, or specialised design combining the single electric machine with a final drive gearbox.

2.1.1. Traditional EV by converting an ICE vehicle. The earliest BEVs were converted from the ICE vehicles [24]. The ICE and fuel tank were replaced by an electric machine and battery pack. To transfer mechanical power from the machine to the wheels, ICE-type transmission components were retained, including a mechanical clutch a, multi-ratio gearbox, and a differential. The gearbox could be manual or automatic [14]. Some of the functions of this transmission are unnecessary with an electric vehicle, e.g. the use of the clutch between the motor and transmission, and the use of a complex multi-speed gearbox for matching the torque-speed characteristics of the power plant to the speed and torque required by the vehicle. (The clutching is entirely unnecessary, and the torque-speed characteristics of the motor are very different from those of 
an engine.) With this topology, there is still a need for a differential to balance the traction force and speed between the left and right traction wheels when travelling along a curved path. This topology was designed to be effective for an ICE, not an electric machine, and as an EV it has poor efficiency and excess mass [25].

2.1.2 Single electric machine with final drive. Electric motors have torque-speed characteristics close to the ideal performance of a vehicle traction power plant, and are able to provide near-maximum power at a wide range of speeds. There is a maximum torque at low speeds, because motor flux is initially constant, but when the machine reaches a base speed, the machine flux weakens while the voltage remains constant. As a result, the motor torque reduces as the speed increases; overall, the power remains constant [9].

With an electric machine, a complex multi-speed transmission is not necessary, and as a result the complexity of the clutch and gearbox can be eliminated. It is possible to use a light motor, typically a small-sized high-speed low-torque motor, together with a single speed high reduction transmission $[10,14,26]$. For a further reduction in mass and inertia, the drive shaft, motor and transmission can be integrated as a single component $[9,10]$, illustrated in Fig. 1(a). This type of BEV is predominant in today's marketplace [5]. However, a central-drive motor with a fixed-ratio still encounters mechan- 
ical loss. Without a variable gearbox, it is there is no possibility of operating the motor at its maximum efficiency [27].

\subsection{Multiple electric machine drive.}

Because electric powertrains are relatively simple, and because an electric machine can be controlled with good precision, it is possible to use more than one machine at a time for example, to have separate motors for each side of a vehicle and/or separate motors for each axle. The following paragraphs describe topologies used in current research vehicles and prototypes.

\subsubsection{Double electric machine with double-axle drive. Whereas a 'conventional'}

EV has a single machine, either at the front or the rear axle, each axle can be driven by a separate and independently controlled motor and gearbox. When two traction sources are combined in a single vehicle in this way with an appropriate control strategy, the designer has more degrees of freedom and the flexibility to explore more effective and efficient operation methods. This powertrain topology is presented in Fig. 1(b). This topology has been sufficiently developed for use in a production vehicle: the Tesla Model X, to be introduced in late 2015, is configured this way, with separate front and rear motors, each with single-ratio gearboxes [28]. Vehicles with this topology are operated with four-wheel drive, and are capable of strong acceleration performance. Tesla, 
for example, claim that the Model X will be capable of accelerating from 0 to $100 \mathrm{~km} / \mathrm{s}$ in less than $5 \mathrm{sec}$, about twice as quickly as a non-performance vehicle [28]. This EV topology still requires the use of a pair of differentials, one front and one rear, which adds mass.

\subsubsection{Multiple electric machines with independently-driven wheels. It is possible} to eliminate the use of differentials by using separate traction motors to drive wheels on the left and right of a vehicle independently: the speed and torque of left and right wheels can be equalised electronically. This tends to improve overall efficiency by reducing vehicle mass [29]. Without gearing, low-speed high-torque motors would be needed, but fixed gearing, belt drive or planetary gearbox can be connected between motor and wheel to provide a better match with commercially-available motors. Even with such gearing, eliminating the differential makes more space available, which may be useful for additional battery capacity and longer range. Moreover, electronic switching loss can be reduced and power electronics can be de-rated [14]. One of the key advantages of this powertrain architecture is an increase in the number of degrees of freedom. With an appropriate energy management strategy, differently-specified multiple motors can configured to spend most of their operating cycle in an more efficient operating envelope than a single motor could achieve, leading to a reduction in energy consumption [27]. The torque balance between left and right wheels must be controlled by 
an electronic differential, which may require complex non-linear control and robust design: failure to operate correctly will cause serious problem for vehicle stability and safety [14]. Furthermore, the cost of two small motors and the associated control units and power electronics is greater than the cost of single equivalently-powered motor and its associated hardware, adding to overall system cost [14, 25].

2.2.3 In-wheel motor drive. Having considered motors closely associated with each wheel, it is natural to wonder whether there would be further benefits integrating the motor into the wheel itself. In-wheel motors for BEVs are the subject of current research [11]; however few passenger cars are using in-wheel motors, and most of those that are still at the research and development stage. In-wheel motor wheels already have applications in mobile robotics $[27,30]$. These applications demonstrate the benefits of in-wheel motors to achieve high mobility. However, such applications involve only at low speeds and focus on the motion of the vehicle rather than energy consumption.

In terms of energy efficiency, the in-wheel motor is integrated into the vehicle wheel which then eliminates all the mechanical gears and the losses associated with transmission [25]. The in-wheel motor can therefore make a vehicle lighter. All power is transferred by wire which gives further benefits in terms of space saving and the flexibility of component arrangement, and also lowers the centre of gravity [26, 31, 32]. In published literature demonstrating the use of a wheel motor on a motorcycle, it has been 
shown that with a wheel motor and using regenerative braking, the overall efficiency can be increased the range by $20 \%$ [33].

For a passenger car application, there are some disadvantages in terms of vehicle performance. As with a vehicle with independently driven non-integrated motors, the in-wheel motor requires an electronic differential to follow curved path; this necessitates complex torque and speed control between the two sides of the vehicle. Moreover, an integrated in-wheel motor increases the wheel mass and inertia, adding to the unsprung mass with negative effects on stability, safety and comfort [13, 14, 31, 34].

By contrast, there are some positive vehicle dynamics aspects of using in-wheel motors. It has been shown that using in-wheel motors with direct drive can have advantages in terms of vehicle stability and control, brought about because the in-wheel motors have quick torque response and allow easy torque measurements [35]. This makes it easier to implement integrated vehicle dynamic control and features such as ABS and dynamic tracking control compared to conventional ICE vehicles $[14,35,36$, 37]. In-wheel drives have been used in a four-wheel drive EV to implement an electrically torque-assisted steering system and global torque control for a four-wheelindependent-drive EV [38]. Because they do not use gearing, in-wheel motors need to be able to produce high torque at low speed, which may result in greater losses compared to a traditional electric motor due to required higher currents. There are efforts to design appropriate machines for this application, such as the axial flux permanent mag- 
netic machine, and this will help in the design and selection of suitable in-wheel motors for use in BEVs $[14,26,31]$.

\subsection{Selected BEV powertrain topologies}

The previous section has presented several architectures with their associated permutations. A subset of these must be chosen for detailed analysis using multi-objective optimization, including a cost-benefit analysis. The literature contains techniques for identifying parameter sets producing the greatest sensitivity in terms of energy consumption [20], highlighting the importance of powertrain efficiency and suggesting that the benefits of multi-ratio transmissions are likely to be marginal. Consequently, variable-ratio gearing systems have not been considered in this work. Four powertrain topologies have been selected for detailed analysis, all using single ratio transmission where appropriate (the in-wheel drive version is naturally gearless so the ratio is unity). The topologies are: single-motor-single-axle (SM-SA) (the Nissan Leaf can be taken as a benchmark), double-motor-double-axle (DM-DA), in-wheel-motor-single-axle (IWMSA) and in-wheel-motor-double-axle (IWM-DA), illustrated in Fig. 1. The significant difference in terms of modelling will be explained next. 


\section{$3 \quad$ Vehicle model and simulation technique}

Vehicle modelling techniques can be classified in two ways: "forward-facing" and "backward-facing". The literature discusses the advantages and disadvantages of these two simulation methods $[18,21]$, and a brief description is provided in the following sections.

\subsection{Forward-facing simulation}

Forward-facing simulation presents a realistic approach to vehicle simulation as it uses a driver model to control the vehicle speed, similar to a human driver controlling a car. Fig. 2 illustrates the structure of a generic forward-facing simulation. Starting from the driver model, the reference speed and actual vehicle speed are compared giving an "error" signal, and this is used to generate a control signal to control the torque used to power the vehicle. (Driver models normally use Proportional-Integral (PI) controllers). In practice, the source of power of the BEV is an electric motor, so an appropriate model is used to translate throttle and brake commands from the driver into torque and mechanical braking signals. Torque from the motor is passed through a model of the transmission and applied to as a force at the wheels. The vehicle's longitudinal dynamics are then modelled: it is usually assumed that we can consider the vehicle as a whole, ignoring separate inertias associated with wheels and machines. Lateral dynamics are ignored. 
The advantage of the forward-facing simulation is that it is realistic because it is of higher fidelity. This method is used for designing vehicle hardware and detailed control development. However, this has to be traded-off against the computation overhead: simulations are expensive and time-consuming.

\subsection{Backward-facing simulation}

Backward-facing simulation uses an opposite approach. Where in "forwards-facing" models, components' inputs are generalized forces and the outputs are generalized motions, in "backwards" models, the generalized motions are the inputs and the generalized forces are the outputs. Consequently, the speed references can drive the system model directly, and a driver model is not required. One assumption made with the backward-facing simulation is that the vehicle will exactly follow the driving cycle as illustrated in Fig. 3. In the diagram, the 'driving profile' is the speed the vehicle is required follow. The traction-resultant forces of the vehicle are calculated from the vehicle model. The principle of conservation of power is applied from one component to the next. The resultant forces and speeds between tyre and road contact patch are converted to torque and angular velocity to the torque and speed required at the gearbox. Then power required from the gearbox, including gearbox losses, is then transferred to the electric motor and battery model. 
Backward-facing simulations generally rely on quasi-static component maps rather than detailed dynamic models. Electric machines are typically modelled using motor efficiency maps. These are look-up tables indicating the efficiency achieved for any required torque and speed pair. The data for this can be collected from the testing of a real electric machine (EM) at steady-state conditions. This simulation type cannot represent dynamical behaviour of components because it is not usually possible to invert the dynamics exactly; this is a disadvantage compared to forward-facing simulation. However, for energy efficiency calculations and optimisation, backward-facing simulations require less time and fewer computational steps compared to those required for forwardsfacing simulations.

\subsection{Vehicle body and environmental losses}

The vehicle model converts the velocity reference into angular velocity and torque at the wheels, as presented in Fig. 4. Angular velocity at the wheels can be calculated from equation (1) while torque at the wheels in equation (2) is calculated from the environmental force - in equation (3) - that applies to the vehicle. Losses from the environmental force result from aerodynamic resistances, tyre rolling resistance and the vehicle climbing the slope. However, this simulation is applied only when the vehicle is moving on the flat road; accordingly, loss from hill climbing is neglected. 


$$
\begin{gathered}
\omega_{\mathrm{w}}(t)=v_{\text {vehicle }}(t) / r_{\mathrm{w}} \\
T_{\mathrm{w}}(t)=F_{\text {vehicle }}(t) \cdot r_{\mathrm{w}} \\
F_{\text {vehicle }}(t)=M g C_{\mathrm{r}}+\frac{1}{2} \rho C_{\mathrm{d}} A v_{\text {vehicle }}^{2}(t)+M \frac{\mathrm{d} v_{\text {vehicle }}(t)}{\mathrm{d} t}
\end{gathered}
$$

where $\omega_{\mathrm{w}}$ the is angular velocity at the wheel, $v_{\text {vehicle }}$ is the vehicle velocity, $r_{\mathrm{w}}$ is the wheel radius, $T_{\mathrm{w}}$ is the torque at the wheel, $F_{\text {vehicle }}$ is the traction force at the centre-ofgravity, $M$ is the vehicle mass, $g$ is the gravitational acceleration, $C_{\mathrm{r}}$ is the vehicle rolling resistance, and $\rho$ and $C_{\mathrm{d}}$ are the air density and the drag coefficient.

\subsection{Transmission}

Like internal combustion engines, electric machines operate most efficiently within a particular speed-torque envelope. With the notable exception of wheel motors, most of the machines used in electric vehicles operate best at higher speeds and lower torques than those encountered at the driveshaft; the transmission transforms the speed-torque pair at the machine to a different speed-torque pair at the driveshaft with equal power. The transmission normally includes several components, but in this work, we consider these using a single 'lumped' gear ratio which describes the overall behaviour. As discussed earlier, there is no need for multiple ratios, and single-ratio transmissions are common on production vehicles [7, 28]. Single-speed transmissions are generally good 
in terms of low drivetrain mass, low volume, high efficiency and low complexity [9, 39].

The calculations for the transmission are expressed as equations (4) and (5).

$$
\begin{gathered}
\omega_{\mathrm{M}}(t)=\omega_{\mathrm{W}}(t) \times(\text { gear ratio }) \\
T_{\mathrm{M}}(t)=\frac{T_{\mathrm{W}}(t)}{\text { (gear ratio }) \times \eta_{G}}
\end{gathered}
$$

where $\omega_{\mathrm{M}}$ and $\omega_{\mathrm{W}}$ are angular velocity at motor and wheel, $T_{\mathrm{M}}$ and $T_{\mathrm{W}}$ are torque at motor and wheel, and $\eta_{\mathrm{G}}$ is efficiency of the transmission.

\subsection{Electric machine modelling}

The electric machine acts as a motor-generator, providing traction torque during acceleration and steady-state driving, and then capturing kinetic energy that would otherwise be 'lost' during braking. A schematic for a backwards model is shown in Fig. 5. The relationship between the motor 'input' power and the 'output' torque-speed pair is given in Equation (6). Note that the machine is not perfectly efficient. When motoring, the machine output power is given by $\eta_{\mathrm{M}} P_{\mathrm{M}}$ where $P_{\mathrm{M}}$ and $\eta_{\mathrm{M}}$ are the power $(\mathrm{kW})$ and efficiency (dimensionless) of the motor. When the equation is arranged as a 'backwards' model the efficiency term appears as a division, rather than a multiplication. The efficiency term $\eta_{\mathrm{M}}<1$ when motoring. (When generating, the equation can be kept the 
same but the efficiency term will need to be set so that $\eta_{M}>1$.) Note that this is a mathematic construct: the system is still 'lossy' in both directions.

The use of a motor map for the backward-facing simulation has been described and for a quasi-static vehicle simulation, it is possible to calculate the energy consumption of the electric machine by using a static map as presented in [40]. Efficiency is calculated as a function of torque, speed and motor parameters (7). (This will be described in greater depth in the next section). The relevant formulae are:

$$
\begin{aligned}
P_{\mathrm{M}}(t) & =T_{\mathrm{M}}(t) \cdot \omega_{\mathrm{M}}(t) / \eta_{\mathrm{M}} \\
\eta_{\mathrm{M}} & =f\left(T_{\mathrm{M}}, \omega_{\mathrm{M}}, \phi_{\mathrm{M}}\right)
\end{aligned}
$$

(Here $\phi_{\mathrm{M}}$ is the motor rating in $\mathrm{kW}$.)

\section{Electric machine modelling with efficiency maps}

A motor efficiency map is a 2D lookup table that contains the motor efficiency information. The motor efficiency is a function of motor torque and speed as described in equation (7). This motor map describes steady-state efficiency and this information is usually collected by measuring the power when motors are tested with a dynamometer. To model machines of different sizes, techniques adapted from the literature were used: in Guzzella et al [3], the machine efficiency map is made scalable to provide a representation of different-sized machines. Guzzella et al's toolbox contains a look-up table of the EM efficiency in both motor mode and generator mode. A similar approach was 
taken in this work. The starting point was the nominal machine map for the case-study vehicle's machine: to scale it, the torque axis was scaled in proportion to the machine's power rating: this principle is illustrated in Fig. 6.

Fig. 7 shows the plot of motor efficiency map which is converted from the original $80 \mathrm{~kW}$ motor of the Nissan Leaf [41]. This map has been used for the optimisation process, this modification assumes that the speed of the motor is limited to $10,500 \mathrm{rpm}$ in every size of motor. A peak torque and efficiency map was constructed for a standard size of the Nissan Leaf motor. The original motor power $(80 \mathrm{~kW})$ and peak torque $(280$ $\mathrm{Nm}$ ) are used as a 'base' map. The torque axis is then scaled representing differentlysized motors. For example, a with a $60 \mathrm{~kW}$ motor, a scale factor of 0.75 is used. A similar technique is used for both traction and regenerative braking. Where the positive torque present the motor efficiency in traction mode and negative torque present the regenerative braking efficiency.

Significant factors which affect the efficiency of electric motors include size, mass and motor cooling. Different powertrain architectures use different numbers of motors and motor sizes. For the same power requirement, the centre drive needs a single, high powered electric motor. On the other hand, the independent drive considers two or four small motors, the total power of which is equal to that requirement. As a result, size, mass and method of motor cooling may influence the powertrain design. In general, a larger motor is likely to be more efficient than a smaller one. When increasing the motor 
power, an increase of the motor speed may result in better motor efficiency than that of motor torque. This is because the losses in the motor are directly proportional to the motor current which is related to torque rather than power. Hence at the same power, a low speed, high torque motor is more likely to have higher losses. In terms of motor size, a high speed motor with gear box is smaller than a low speed high torque motor alone [25].

\subsection{Modified motor map for in-wheel motors}

In the first two cases (SM-SA, DM-DA), a scalable motor map of the permanent magnet synchronous machine motor is used, as presented in Fig. 8. However, for the in-wheel motor vehicle (IWM-SA, IWM-DA), the torque and speed characteristics are different, as in-wheel motors require a high torque with low speed. For a reasonable comparison between a conventional and an in-wheel motor, the in-wheel motor efficiency map is based on the original map of the Nissan Leaf. The torque and speed scale were modified to match in-wheel motors available in the market $[42,43]$. Specifications from a manufacturer of in-wheel motors shows a peak torque of around $700 \mathrm{Nm}$ and a maximum speed around $2000 \mathrm{rpm}$ : the original motor map provides a peak torque at $280 \mathrm{Nm}$, based on a speed of $280 \mathrm{rad} / \mathrm{s}$ and a max speed of $1100 \mathrm{rad} / \mathrm{s}$ and delivers up to $80 \mathrm{~kW}$ of power. For the in-wheel motor, the torque scale is extended by a factor of 2.5 at the torque axis to get the max torque to $700 \mathrm{Nm}$ and based on a speed of $53 \mathrm{rad} / \mathrm{s}$ and a max 
speed of $210 \mathrm{rad} / \mathrm{s}$. The peak power becomes $38.5 \mathrm{~kW}$ as presented in Fig. 8. The scaling has been chosen so that the in-wheel motor map represents half the power of the original map because the in-wheel vehicle requires at least two identical motor to drive each wheel (for single axis drive), and each only needs to provide half the overall power.

\subsection{Battery}

The battery is the main source of energy for the BEV. It is an electrochemical device that stores electrical energy in the form of chemical energy. In this research, a simple battery model is used. A static model of this battery model consists of an open-circuit voltage source and an internal resistance. A schematic is presented in Fig. 9.

3.7.1 State-of-charge (SOC). Battery SOC is the amount of charge $Q(t)$ that remains in the battery relative to the capacity of the battery $Q_{\text {bat }}(\mathrm{Ah})$ as illustrated in equation (8). The initial charge of the battery is denoted by $Q_{\text {initial }}$.

$$
\begin{gathered}
\text { SOC }=Q(t) / Q_{\text {bat }} \\
Q(t)=Q_{\text {init }}-\int I_{\mathrm{T}, \mathrm{bat}}(t) d t
\end{gathered}
$$

$I_{\mathrm{T}, \mathrm{bat}}(t)$ is the terminal current of the battery, where positive current discharges the battery and negative current charges it. The current at the terminal of the battery can be 
calculated as a function of power that is required from the battery and the terminal voltage of the battery, as described in equation (11).

$$
\begin{gathered}
I_{\mathrm{T}, \mathrm{bat}}(t)=P_{\mathrm{M}} / V_{\mathrm{T}, \mathrm{bat}} \\
V_{\mathrm{T}, \text { bat }}=V_{\mathrm{OCV}, \mathrm{bat}}-I_{\mathrm{T}, \mathrm{bat}}(t) \cdot R_{\mathrm{i}, \mathrm{bat}}
\end{gathered}
$$

The terminal voltage $V_{\mathrm{T}, \mathrm{bat}}$ is calculated from the open circuit voltage $V_{\mathrm{OCV} \text {,bat }}$ as shown in Fig. 10 and the internal cell resistance $R_{\mathrm{i}, \text { bat }}$ in equation (11). By substituting current $I_{\mathrm{T}, \text { bat }}(t)$ from equation (10) into (11), the terminal voltage can be calculated as the function of power, open circuit voltage and internal resistance in equation (13).

$$
\begin{gathered}
V_{\mathrm{T}, \mathrm{bat}}^{2}-V_{\mathrm{OCV}, \mathrm{bat}} \cdot V_{\mathrm{T}, \mathrm{bat}}+P_{\mathrm{M}} \cdot R_{\mathrm{i}, \mathrm{bat}}=0 \\
V_{\mathrm{T}, \mathrm{bat}}=\frac{V_{\mathrm{OCV}, \mathrm{bat}}+\sqrt{V_{\mathrm{OCV}, \mathrm{bat}}^{2}-4 \cdot P_{\mathrm{M}} \cdot R_{\mathrm{i}, \mathrm{bat}}}}{2}
\end{gathered}
$$

3.7.2 Pack-level calculations. Battery terminal voltage and battery capacity are calculated from the series-parallel combinations of battery cells, as shown in Fig. 10. The open circuit voltage of a battery pack is calculated from the open-circuit voltage of a cell and the number of cells in series, as shown in equation (14). Battery capacities can be calculated by equation (15)

$$
V_{\mathrm{OCV}, \mathrm{bat}}=V_{\mathrm{OCV}, \mathrm{cell}} \cdot N_{\text {series }}
$$




$$
(\text { battery capacity })_{k W h}=N_{\text {series }} N_{\text {parallel }} \cdot(\text { cell capacity })_{k W h}
$$

where $N_{\text {series }}$ and $N_{\text {parallel }}$ are the number of cells in series and parallel.

\subsection{Motor torque split control}

To simultaneously drive a vehicle with more than one axle, for example a four-wheeldrive vehicle, there is a need for a device to split the torque between the axles. For the conventional vehicle (ICE), this is achieved with a central differential. For the BEV, the a torque-split can also be used to maximise energy efficiency: for any given power demand, there will be an optimally efficient way of splitting torque between front and rear machines. When a quasi-static model is assumed, this optimal split can be achieved with a deterministic algorithm, which selects the most efficient operating point for each motor using the torque-speed curves and efficiency maps. The front and rear motors can be the same size or different sizes and the effects of transmission can be taken into account - it is possible to use different ratios for front and rear. Calculation is easy, and does not require on-line optimization: in the model, the torque split function was implemented using a look-up table to create a split ratio as presented in equations (16)(20)

The total motor output is given by:

$$
P_{\text {out,total }}=\left(T_{\mathrm{F}} \cdot \omega_{\mathrm{M}, \text { front }}\right)+\left(T_{\mathrm{R}} \cdot \omega_{\mathrm{M}, \text { rear }}\right)
$$


where $T_{\mathrm{F}}, \omega_{\mathrm{M} \text {,front }}$ are the torque and speed of the front machine and $T_{\mathrm{R}} \omega_{\mathrm{M} \text {,rear }}$ are the torque and speed of the rear machine. These can be related to the wheel speeds via the front and rear gear ratios $G_{\mathrm{F}}$ and $G_{\mathrm{R}}$ :

$$
P_{\text {out,total }}=T_{\mathrm{F}}\left(\omega_{\mathrm{w}} / G_{\mathrm{F}}\right)+T_{\mathrm{R}}\left(\omega_{\mathrm{w}} / G_{\mathrm{R}}\right) \text {. }
$$

It is possible to express $T_{\mathrm{F}}$ as a fraction $T_{\mathrm{S}}$ of the required torque it would need to supply if only the front motor was used:

$$
T_{\mathrm{F}}=T_{\mathrm{S}}\left(\frac{P_{\text {out }, \text { total }}}{\omega_{\mathrm{w}} / G_{\mathrm{F}}}\right)
$$

This then requires an equivalent relationship for the rear:

$$
T_{\mathrm{R}}=\left(1-T_{\mathrm{S}}\right) \frac{P_{\text {out }, \text { total }}}{\omega_{\mathrm{w}} / G_{\mathrm{R}}}
$$

If the machine efficiencies are functions of torque and speed $\eta_{\mathrm{F}}\left(T_{\mathrm{F}}, \omega_{\mathrm{F}}\right)$ and $\eta_{\mathrm{R}}\left(T_{\mathrm{R}}, \omega_{\mathrm{R}}\right)$, the problem becomes how to minimize the instantaneous power, i.e.

$$
P_{\text {in,total }}=\frac{T_{\mathrm{F}} \cdot \omega_{\mathrm{M}, \text { front }}}{\eta_{\mathrm{F}}\left(T_{\mathrm{F}}, \omega_{\mathrm{F}}\right)}+\frac{T_{\mathrm{R}} \cdot \omega_{\mathrm{M}, \text { rear }}}{\eta_{\mathrm{R}}\left(T_{\mathrm{R}}, \omega_{\mathrm{R}}\right)}
$$

which is given by

$$
T_{\mathrm{S}}=\arg \min \left(\frac{T_{\mathrm{S}} \cdot P_{\text {out,total }}}{\left.\eta_{\mathrm{F}}\left(T_{\mathrm{S}}\left(\frac{P_{\mathrm{out}, \text { total }}}{\omega_{\mathrm{w}} / G_{\mathrm{F}}}\right)\right), \omega_{\mathrm{w}} / G_{\mathrm{F}}\right)}+\frac{\left(1-T_{\mathrm{S}}\right) P_{\text {out total }}}{\left.\eta_{\mathrm{R}}\left(\left(1-T_{\mathrm{S}}\right) \frac{P_{\text {out,total }}}{\omega_{\mathrm{w}} / G_{\mathrm{R}}}\right), \omega_{\mathrm{w}} / G_{\mathrm{R}}\right)}\right)
$$

This is a static relationship for any given output-power and wheel-speed pair, and can be precomputed as a look-up table for convenient implementation. 
Fig. 11 presents the operating points of $48 \mathrm{~kW}$ front and $32 \mathrm{~kW}$ rear motors. The total of $100 \mathrm{Nm}$ torque required from both motor. The torque split function select the operating point of $60 \mathrm{Nm}$ torque from the front motor and $40 \mathrm{Nm}$ from the rear motor. At $60 \%$ front split ratio, both motor operated at the minimum of energy consumption as presented in Fig. 12.

The torque-splitting algorithm is used in traction mode only; the torque split in regenerative braking remains constant, depending on the size of the motors, as presented in equation (21). During braking, this approach cannot be used: vehicle stability could potentially become an issue, so there are strict legislative requirements governing the proportion of the braking force that can be applied at each axle. The torque-splitting algorithm when accelerating the vehicle or maintaining constant speed. During braking, the following formula is used:

$$
T_{\mathrm{SB}}=\frac{\phi_{\mathrm{F}}}{\phi_{\mathrm{F}}+\phi_{\mathrm{R}}}
$$

where $T_{\mathrm{SB}}$ is torque split in braking mode, $\phi_{\mathrm{F}}$ is the front motor rating $(\mathrm{kW})$ and $\phi_{\mathrm{R}}$ is the rear motor rating $(\mathrm{kW})$. This ensures that the braking force from the front wheels will always be greater than or equal to the braking force from the rear wheels. 


\subsection{Mass of vehicle}

In this section, we investigate the effect of different vehicle topologies, as discussed before, on energy consumption and acceleration performance. One of the important vehicle parameter which impacts energy consumption is vehicle mass [20]. The vehicle mass is calculated by consideration of three components: electric machine and transmission (combined), battery, and vehicle body.

3.9.1 Mass of transmission and electric machine. For mass calculations, the EM and its transmission are treated as a single unit. For the SM-SA and DM-DA, each axle is equipped with a single ratio transmission only and it is assumed that the difference in mass between gearboxes with different transmission ratios is negligible. The mass of the motor is estimated by using the average mass of the permanent magnet motors available commercially [44]. Table 1 gives the formulae used.

Table 2 details assumptions made on the mass of transmission components. In the DM-DA type, $30 \mathrm{~kg}$ of additional transmission is added to the total vehicle mass; a 25\% mass reduction has been applied to the overall powertrain mass for in-wheel vehicles as they do not have a transmission and drive shaft.

From these tables it can be seen that if the vehicle has a fixed EM power $(80 \mathrm{~kW}$ SM-SA and $40+40 \mathrm{~kW}$ DM-DA) the DM-DA type is always heavier than the SM-SA. This is not a surprise, and if nothing else about a vehicle changed, a DM-DA powertrain 
would need to be operated more efficiently to provide an advantage in terms of energy consumption relative to SM-SA.

3.9.2 Mass of battery. The mass of the battery pack was estimated from the number of cells in the battery. The cells and pack size used in the Nissan Leaf [42] were used as a baseline: each cell has a mass of $0.787 \mathrm{~kg}$; there are four cells in one module and 48 modules in a battery pack, giving a total cell mass of 0.787 x 4 x $48=151.1 \mathrm{~kg}$. It will be assumed that a battery will also require $0.06 \mathrm{~kg} / \mathrm{kW}$ for the mass of thermal management system and $0.14 \mathrm{~kg} / \mathrm{kW}$ for the mass of harness and bus bar [43]: this gives an effective total cell mass of $0.975 \mathrm{~kg}$ per cell. Using these assumptions, the total mass of case-study Nissan Leaf was estimated at $187.2 \mathrm{~kg}$. In this work, the mass of the battery in every topology will be calculated using the same formula, since a similar type of battery pack will be assumed, though the number of cells will be allowed to vary.

3.9.3 Calculation of vehicle kerb mass. For these calculations, it was assumed that the vehicle would be of a similar type to the original case-study vehicle, a C-segment passenger car. A vehicle's mass can be considered to consist of the mass of the powertrain plus a 'glider mass', i.e. the fixed mass of the vehicle without the powertrain components. (This terminology comes from the aerospace domain: an aircraft without an engine is a 'glider' in a literal sense!) The total mass of the case study vehicle, $M_{\text {orig }}$, is $1521 \mathrm{~kg}$. To estimate the 'glider mass' $M_{\text {glider }}$, the mass of the case study vehicle's 
powertrain $M_{\text {PTorig }}$ was estimated using the formulas already presented; this was subtracted from the total mass to get an estimate of the glider mass:

$$
M_{\text {glider }}=M_{\text {orig }}-M_{\text {PTorig }}
$$

This calculation described assumes that the glider mass is unaffected by the choice of powertrain. In practice, this is unlikely to be true: a heavier powertrain will probably require a stronger and heavier chassis, for example. To model this, it was assumed that the chassis would be made heavier by 0.6 times the increase in powertrain mass:

$$
M_{\text {new }}=M_{\text {glider }}+M_{\text {PTnew }}+0.6\left(M_{\text {PTnew }}-M_{\text {PTorig }}\right)
$$

or, more simply:

$$
M_{\text {new }}=M_{\text {orig }}+1.6\left(M_{\text {PTnew }}-M_{\text {PTorig }}\right)
$$

\subsection{Calculation of powertrain cost}

Table 3 gives the equations and the assumptions made for calculating the powertrain cost. These equations based on the long-term pricing estimates from the literature [44]. The pack cost is based on the capacity of the pack and the cell cost, itself dependent on the power-to-energy ratio of the cells, $P / E$ - this has been taken as 4.0 based on the information available for the Nissan Leaf [45]. The formula for cost is

$$
(\text { cell cost })_{\$ / \mathrm{kWh}}=11.1 \times(P / E)+221.1
$$




$$
\operatorname{cost}_{\text {battery pack }}(\$)=\left((\text { cell cost })_{\$ / \mathrm{kWh}}+13\right) \times(\text { cell capacity })_{k W h}+680
$$

Total powertrain mass and cost are calculated based on the mass and cost of the motor:

$$
(\text { cost })_{\text {powertrain }}=(\cos t)_{\text {motor }}+(\operatorname{cost})_{\text {powertrain }}+(\text { cost })_{\text {battery pack }}
$$

Details of these calculations may be found in Table 3 .

\subsection{Drivability (acceleration time) calculation}

Driveability is assessed through a simple calculation estimating the time taken to accelerate from rest to $100 \mathrm{~km} / \mathrm{h}$.

Assume that the quasi-static representation of the system is correct. Given a vehicle of constant mass $M$, let $v(t)$ be the vehicle's instantaneous speed, and let $f_{w}(v)$ be the maximum tractive force at that speed. Consider Newton's second law applied over a small time window:

$$
f_{w}(v)=\frac{M(v+\delta v)-M v}{\delta t}
$$

Rearranging this gives

$$
\delta t=\frac{M}{f_{w}(v)} \delta v
$$

Summing both sides over the acceleration period and taking the limit gives:

$$
T=\int_{0}^{T} d t=\int_{0}^{V} \frac{M}{f_{w}(v)} d v
$$


where $V$ is a specified speed and $T$ the time taken to reach that speed. Thus, the time taken to reach a speed of $100 \mathrm{~km} / \mathrm{h}(27.78 \mathrm{~m} / \mathrm{s})$ from rest can be estimated from equation (30):

$$
\text { (acceleration time) })_{0-100 \mathrm{~km} / \mathrm{h}}=T_{100}=\int_{0}^{27.78} \frac{M}{f_{\mathrm{w}}(v)} d v
$$

where $T_{100}$ is the time taken to accelerate from rest to $100 \mathrm{~km} / \mathrm{h}$.

\section{$4 \quad$ Vehicle simulations without optimization}

In order to understand the implications of each chosen topology, two studies were carried out. In the first study, the properties of each topology with an $80 \mathrm{~kW}$ electric machine were considered. The battery back was kept at the 'case study' size, and there were no attempts to optimize the powertrain. The aim of this part of the study was to demonstrate that the basic methodology was sensible, and that the simulations gave reasonable results.

For the first topology, SM-SA, a single $80 \mathrm{~kW}$ motor at a front axle is used - as in the case-study vehicle. For the DM-DA topology, two identical motors are applied, one at the front and the other at the rear. For the IWM-SA a two $40 \mathrm{~kW}$ in-wheel motors are used, one each at the left and right side of the front axle; for the IWM-DA, four $20 \mathrm{~kW}$ in-wheel motors are used. Table 4 shows the difference in powertrain masses: the DMDA will have the most extra mass because of it is using an additional motor and gear- 
box at the rear axle. For in-wheel topologies, four motors are used, but this is offset by the reduction in powertrain mass brought about by the omission of gearing.

Table 5 shows the results of simulation: energy consumption, acceleration time and powertrain cost It can be seen that both the in-wheel motor vehicles consume less energy than the original case study vehicle. The 'worst' is the DM-DA vehicle, though despite its mass increasing by over $3 \%$ or $50 \mathrm{~kg}$ added due to the rear axle motor and transmission, the energy consumption has only increased by around $1 \%$ compared to the case study vehicle - this is because of efficiencies arising from the motor torque split that divides the vehicle torque between the front and rear axles efficiently.

\section{$5 \quad$ Multi-objective optimization on different BEV topologies}

To get a 'fair' comparison of the benefits of each topology, it is important to assess it at its best. This means optimizing the whole powertrain, with all significant parameters machine power, battery sizing and - where appropriate - gear ratios. For the DM-DA topology, the front and rear machines were permitted different motor sizing and gear ratios.

The multi-objective optimisation problem chosen for this exploration considered the simultaneous minimisation of three objectives: firstly, 'real-world' energy consumption over the combined Artemis driving cycle (CADC); secondly, acceleration time from 0$100 \mathrm{~km} / \mathrm{h}$; thirdly, powertrain cost. These three objective functions are equally 
weighted. A constraint on range was applied: when using the NEDC - currently required for legislative statements in the UK - the range of the vehicle had to be at least $175 \mathrm{~km}$. This will ensure that any vehicle produced will give comparable range to the Nissan Leaf. Optimization was performed using readily-available genetic algorithm (GA) solvers from the MATLAB R2014a Global Optimization Toolbox's 'ga' command; the user's guide for this software goes into some depth on the details of the algorithms used [46]. It is beyond the scope of this paper to describe the detail in depth, but it may aid the reader to recap the fundamentals here. The essential idea of a genetic algorithm is to mimic Darwinian 'evolution by natural selection.' In place of the usual objective function, GA theorists talk about a scalar-valued 'fitness function.' Any given point in the optimization space will have a fitness function. The idea is to start with a random 'population' of points in the design space, to select the 'fittest' (i.e. those with the best objective function values), then to 'cross-breed' the selected points to create 'children' with inherited properties which are a mix of those of their 'parents'; to ensure that this is not too limiting, the children may also incorporate 'mutations,' introducing a degree of randomness into the process. Over successive 'generations', the population will tend to become 'fitter', and eventually converge the 'fittest' possible. As with all attempts at non-convex optimization (other than the impossible fully-exhaustive search), there is always a risk that the process will settle on a sufficiently attractive local minimum rather than the true global minimum, though the fact that the initial points are 
distributed through the design space and the presence of mutations may help to reduce this risk. A degree of confidence may be obtained from the fact that GAs have been successfully used in powertrain component sizing optimization, where they have confirmed the near-optimality of the Nissan Leaf [47].

A mathematical formulation for the problem of this paper is given in equations (31) to (35):

Minimize

$$
J_{1}\left(X_{\mathrm{D}}\right), J_{2}\left(X_{\mathrm{D}}\right), J_{3}\left(X_{\mathrm{D}}\right)
$$

where

$$
\begin{gathered}
J_{1}\left(X_{\mathrm{D}}\right)=E\left(X_{\mathrm{D}}\right)=\text { cycle energy consumption } \\
J_{2}\left(X_{\mathrm{D}}\right)=(\text { aceleration time })_{0-100 \mathrm{~km}} \\
J_{3}\left(X_{\mathrm{D}}\right)=(\text { cost })_{\text {powertrain }}
\end{gathered}
$$

Subject to

$$
\text { range }(\mathrm{NEDC}) \geq 175 \mathrm{~km}
$$

where $X_{\mathrm{D}}$ is a vector of vehicle parameters such as motor size, gear ratio and battery capacities. $T$ is time of a driving cycle in second. The results of the multi-objective optimization are shown in Fig. 13 and 14. Fig. 13 shows the trade-offs of between the energy consumption and acceleration time for each topology. The solid line shows as a benchmark the acceleration of the Nissan Leaf, $9.9 \mathrm{sec}$ for $0-100 \mathrm{~km} / \mathrm{h}$. For each topol- 
ogy, it is possible to match or improve the original acceleration performance relative to the benchmark vehicle - this is most noticeable for the topologies using in-wheel motors. Better acceleration naturally requires a large motor with more mass, and therefore consumes more energy. Table 6 shows the energy consumption at the benchmark acceleration. To meet this performance whilst minimizing energy efficiency, the paretooptimal solutions for every topology required at least an $80 \mathrm{~kW}$ of motor. The IWM-DA gives the best energy efficiency result with an improvement of more than $3 \%$ compared to the benchmark vehicle. The optimized SM-SA vehicle type can be considered as the optimized form of the case study vehicle. To obtain the same acceleration performance, the motor size remained the same, but the pareto-optimal efficiency was achieved using a slightly larger gear ratio and a smaller battery compare to the original vehicle. This does not in any sense mean that the original case study vehicle was 'wrong:' it may well be that the manufacturers had slightly different objectives in mind for their design process. It is if anything reassuring for this methodology to find how close our optimal solution is to their design .

It is clear from this that if getting maximum efficiency for a given acceleration performance is required, then the in-wheel motor topologies are the best choice. In particular, the best trade-off is obtained with the IWM-DA configuration. It should be noted however that this is also likely to be the most expensive powertrain. 
So far, we have looked at the trade-offs between energy consumption and performance.

Fig. 14 shows another trade-off: energy consumption versus powertrain cost. In this case, the incumbent SM-SA topology is gives the best trade-off curve, with the IWMSA topology the second best. The lowest costs achievable relative to the benchmark vehicle's energy consumption are shown in Table 7. The cheapest powertrain was achieved with a slightly larger motor and gear ratio $(84 \mathrm{~kW}, 8.9: 1)$ and a slightly smaller battery size. The powertrain was $2.3 \%$ cheaper than the original case study vehicle. The other topologies produced more expensive vehicles, though the additional costs were not uniform: the IWM-SA was about $1 \%$ more expensive, while the IWM-DA was about $26 \%$ more expensive. There is a clear conflict here: the IWM-DA machine was the best in terms of energy consumption versus acceleration, but it is the worst in terms of cost. The SM-SA is the cheapest for a given efficiency, but the worst performing. The IWM-SA gives a reasonable compromise between all three objectives. The costs and benefits of each topology can be summarized:

\section{$5.1 S M-S A$}

The SM-SA is the simplest BEV powertrain, using a topology close to a traditional mechanical layout including a fixed ratio gearbox and a large single power source. This is low cost, and simple to control. The smallest motor size that could complete the com- 
plete Common Artemis Driving Cycle was $60 \mathrm{~kW}$ - this solution has poor acceleration but consumes minimum energy. This topology's greatest benefit is its low cost, but it does not give a good trade-off between energy consumption and performance.

\section{$5.2 \quad D M-D A$}

This BEV topology used two separate motors for front and rear axles. By allowing different motor sizing and gear ratios in front and rear, it was possible to achieve improved energy efficiency and acceleration performance compared to the baseline vehicle and the SM-SA type. However, it was relatively expensive for any given energy consumption. It was much cheaper than the IWM-DA vehicle for a given acceleration. The DM-DA is most useful for a 'cheap' performance car or 4WD vehicle: in both these scenarios, IWM-DA vehicle would give better performance but be much more expensive: DM-DA is reasonable and more affordable.

\section{$5.3 \quad I W M-S A$}

IWM-SA was slightly more expensive than the SM-SA vehicle. It was able to give better energy consumption and better acceleration performance. This is good for passenger cars that do not need 4WD for very high performance. This topology may well be suitable for the future small city car. Complexity of control and consideration of electronic 
differential algorithms were not considered, neither was the increased unsprung mass. These problems are likely to be surmountable with further work.

\section{$5.4 \quad I W M-D A$}

IWM-DA produced a good acceleration time with minimum energy consumption, but was the most expensive topology. It is excellent for efficient performance vehicles, but it is expensive. Where 4WD is not required, IWM-SA may provide a better compromise between all three objectives.

Fig. 15 gives guidelines on the selection of an appropriate topology to meet any given combination of objectives. For a general all-round vehicle, the IWM-SA and SM-SA topologies are likely to prove the best.

\subsection{Robustness of solutions}

In order to test the robustness of the solutions obtained, the optimization was repeated, but the vehicle's maximum payload of $395 \mathrm{~kg}$ was assumed. The results are shown in Fig. 16 and Fig. 17. It will be seen that the results have changed significantly:

- For the compromise between efficiency and driveability, the IWM-SA topology is the best choice. The IWM-DA topology is second best. 
- For the compromise between efficiency and powertrain cost, the SM-SA vehicle is still significant.

- For the compromise between driveability and cost, the IWM-SA is still a good choice, but not significantly different to the SM-SA.

Whether these results should take precedence over the results for the unladen vehicle will depend very much on the way the car manufacturers interpret consumer desires.

\section{Conclusions}

In this paper a study has been presented in which the properties of four possible battery electric vehicle topologies were studied. The topologies used different combinations of in-body and in-wheel motors, driving axles and powertrain arrangements. The background to the topologies was presented, and four topologies selected for detailed analysis were described: single-motor single-axle (SM-SA), dual-motor dual-axle (DM-DA), in-wheel motor single axle (IWM-SA) and in-wheel motor dual axle (IWM-DA). These were modelled, and the calculations, and assumptions used by the authors were presented. The results of the models were presented, first showing how each topology performed with a fixed $80 \mathrm{~kW}$ total motor power, and then after performing multiobjective optimization. The relative benefits of each topology were explored and presented with guidelines on the choice of topology for given objectives. For pure energy efficiency or a good compromise between energy efficiency and driving performance, 
the IWM-DA topology was best; for pure driving performance, the DM-DA topology was best; for a cheap vehicle or a good compromise between cost and efficiency, SMSA was best, and for a cheap vehicle with good performance, IWM-SA was best. Also, there was significant sensitivity of the result to the problem formulation, as shown by the addition of a full payload to the vehicle. These guidelines and the method used to obtain them may be useful for vehicle manufacturers in determining the best topologies to explore in the design of future BEVs.

\subsection{Future Work}

There are a number of potential avenues for future exploration:

1. The impact of driverless cars on powertrain configuration could be considered. At present, powertrain sizing is constrained by a need to provide user-friendly ‘driveability' properties. Broadly speaking, this requires powertrains to be sized for high torque capabilities, which perhaps are not strictly needed for satisfactory progression. A planned study will consider an self-driving urban vehicle perhaps a 'future taxi' - and understand the distinctive aspects of optimization of such a powertrain.

2. The techniques used in this study can be applied to explore the powertrains best suited to non-traditional power sources (such as lithium-sulfur batteries), or for non-passenger (i.e. freight) road transport applications. The fundamental princi- 
ples here will not be different, but the duty cycles and the relative importance of some of the vehicle properties will change dramatically.

3. The metrics so far have been powertrain cost, efficiency and performance. There is a growing body of work that considers the relationship between usage and component lifespan. This would be valuable to explore. 


\section{References}

1. European Commission. Road Vehicles. Transport \& Environment, http://ec.europa.eu/environment/air/ transport/road.htm (accessed 27 August 2014).

2. [UK] Department for Transport. Regulations on emissions. Department website, www.dft.gov.uk (accessed 27 August, 2014).

3. Guzzella L and Sciarretta A. Vehicle Propulsion Systems: Introduction to Modeling and Optimization. Springer, 2005.

4. Dextreit C, Assadian F, Kolmanovsky V, Mahtani J and Burnham K. Hybrid electric vehicle energy management using game theory. SAE paper 2008-01$1317,2008$.

5. Dextreit C and Kolmanovsky V. Game theory controller for hybrid electric vehicles. IEEE Trans. Control Systems Technology 2014; 22(2): 652-663.

6. Weissinger C, Buecherl D and Herzog H. Conceptual design of a pure electric vehicle. In: 2010 IEEE Vehicle Power and Propulsion Conf. (VPPC), pp. 1-5.

7. Hayes JG, Oliveria RPR, Vaughan S and Egan MG. Simplified electric vehicle power train models and range estimation. In: Proc. 2011 IEEE Vehicle Power and Propulsion Conference (VPPC), pp. 1-5. 
8. Pearre NS, Kempton W, Guensler RL, V. and Elango V. Electric vehicles: how much range is required for a day's driving? Transportation Research Part C: Emerging Technologies 2011; 19(6): 1171-1184.

9. Ehsani M, Gao Y and Emadi A. Modern Electric, Hybrid Electric, and Fuel Cell Vehicles: Fundamentals, Theory, and Design. 2nd ed. Boca Raton, FL: CRC Press, 2009, p. 557.

10. Guiron Z, Henghai Z, and Houyu L. The Driving Control of Pure Electric Vehicle. Procedia Environmental Sciences 2011; 10(A): 433-438.

11. Wang R, Chen Y, Feng D, Huang X and Wang J. Development and performance characterization of an electric ground vehicle with independently actuated inwheel motors. J. Power Sources 2011; 196(8): 3962-3971.

12. Lightning Car Company. A new way of motoring, http://www.lightningcarcompany.co.uk (accessed 27 August 2014).

13. van Schalkwyk DJ and Kamper MJ. Effect of hub motor mass on stability and comfort of electric vehicles. In: 2006 IEEE Vehicle Power and Propulsion Conf. (VPPC).

14. Jain M and Williamson SS. Suitability analysis of in-wheel motor direct drives for electric and hybrid electric vehicles. In: 2009 IEEE Electrical Power and Energy Conf. (EPEC). 
15. Xinxiang $Y$ and Patterson D. Improvement of drive range, acceleration and deceleration performance in an electric vehicle propulsion system. In: 30th Annual IEEE Power Electronics Specialists Conference, 1999 (PESC 99).

16. Benysek $G$ and Jarnut $M$. Electric vehicle charging infrastructure in Poland. Renewable and Sustainable Energy Reviews 2012; 16(1): 320-328.

17. Zhou B, Qinghua J, Yi Y and Jisheng W. Analysis of energy consumption and powertrain parameters optimization of BEV based on running cycle. In: 2010 IEEE 11th Int. Conf. Computer-Aided Industrial Design and Conceptual Design (CAIDCD).

18. Wipke KB, Cuddy MR and Burch SD. ADVISOR 2.1: a user-friendly advanced powertrain simulation using a combined backward/forward approach. IEEE Trans. Vehicular Technology 1999; 48(6): 1751-1761.

19. Hu X, Murgovski N, Johannesson L M and Egardt B. Optimal Dimensioning and Power Management of a Fuel Cell/Battery Hybrid Bus via Convex Programming. IEEE/ASME Trans. Mechatronics 2016; 20(1): 457-468.

20. Othaganont P, Assadian F, and Auger D. Sensitivity analyses for cross-coupled parameters in automotive powertrain optimization. Energies 2014; 7(6): 37333747. 
21. Mohan G, Assadian F and Longo S. Comparative analysis of forward-facing models vs backward-facing models in powertrain component sizing. In: 2013 4th IET Hybrid and Electric Vehicles Conference (HEVC 2013).

22. Yang Y, Hu X, Pei H and Peng Z. Comparison of power-split and parallel hybrid powertrain architectures with a single electric machine: Dynamic programming approach. Applied Energy 2016; 168: 683-690.

23. Mohan G, Assadian F and Longo S. An Optimization Framework for Comparative Analysis of Multiple Vehicle Powertrains. Energies 2013; 6: 5507-5537.

24. Leitman S and Brant B, Build Your Own Electric Vehicle. 2nd ed., New York: McGraw-Hill, 2009.

25. Larminie J and Lowry J. Electric Vehicle Technology Explained. Chichester, U.K.: Wiley, 2004.

26. Chen GH and Tseng KJ. Design of a permanent-magnet direct-driven wheel motor drive for electric vehicle. In: 27th Annual IEEE Power Electronics Specialists Conf., 1996 (PESC '96).

27. Huihuan Q, Xu G, Yan Q et al. Energy management for four-wheel independent driving vehicle. In: 2010 IEEE/RSJ International Conf. Intelligent Robots and Systems (IROS).

28. Tesla Motors. Company website, http://www.teslamotors.com (accessed $27 \mathrm{Au}-$ gust 2014). 
29. Caricchi F et al. Prototype of electric vehicle drive with twin water-cooled wheel direct drive motors. In: 27th Annual Power Electronics Specialists Conference, 1996 (PESC '96).

30. Qian $\mathrm{H}$ et al. System and design of an Omni-directional vehicle. In: IEEE Int. Conf. Robotics and Biomimetics, 2008 (ROBIO 2008).

31. Rahman KM et al. Application of Direct-Drive Wheel Motor for Fuel Cell Electric and Hybrid Electric Vehicle Propulsion System. IEEE Trans. Industry Applications 2006; 42(5): 1185-1192.

32. Tao $\mathrm{G}$ et al. A novel driving and control system for direct-wheel-driven electric vehicle. In: 2004 12th Symposium on Electromagnetic Launch Technology.

33. Yee-Pien Y and Tsung-Hsien H. A new energy management system of directlydriven electric vehicle with electronic gearshift and regenerative braking. In: American Control Conference, 2007 (ACC '07).

34. Tie SF and Tan CW. A review of energy sources and energy management system in electric vehicles. Renewable and Sustainable Energy Reviews 2013; 20: $82-102$.

35. Dejun Y. and Hori Y. A novel traction control of EV based on maximum effective torque IEEE 2008 Vehicle Power and Propulsion Conf. (VPPC '08). 
36. Hori Y. Future vehicle driven by electricity and control-research on four wheel motored "UOT Electric March II". In: 2002 7th Int Workshop on Advanced Motion Control.

37. Sakai S, Sado H and Hori Y. Motion control in an electric vehicle with four independently driven in-wheel motors. IEEE/ASME Trans Mechatronics 1999; 4(1): 9-16.

38. Wang $\mathrm{J}$ et al. Independent wheel torque control of $4 W D$ electric vehicle for differential drive assisted steering. Mechatronics 2011; 21(1): 63-76.

39. Sorniotti A et al. Optimization of a multi-speed electric axle as a function of the electric motor properties. In: 2010 IEEE Vehicle Power and Propulsion Conf. (VPPC).

40. Lukic SM and A Emado A. Modeling of electric machines for automotive applications using efficiency maps. In: Electrical Insulation Conference and Electrical Manufacturing Coil Winding Technology Conference, 2003..

41. Sato Y et al. Development of high response motor and inverter system for the Nissan LEAF electric vehicle. SAE paper 2011-01-0350, 2011.

42. Protean Electric. In-wheel motor, torque-speed characteristics. Company website, http://www.proteanelectric.com (accessed 7 July 2015).

43. YASA. In-wheel motor torque-speed characteristics. Company website, http://www.yasamotor.com (accessed 7 July 2015). 
44. Simpson A. Cost-benefit analysis of plug-in hybrid electric vehicle technology. In: 22th Int. Battery, Hybrid and Fuel Cell Electric Vehicle Symposium and Exhibition. 2006: Yokohama, Japan.

45. Nissan Motor Co. LEAF battery specifications. EV/HEV Safety, www.nhtsa.gov/pdf/ev/Nissan_Presentation-Bob_Yakushi.pptx (2012, accessed 7 July 2015).

46. The MathWorks, Inc. Global Optimization Toolbox R2014a User's Guide. Natick, MA: The MathWorks, Inc., 2014, sec. 5.3.

47. Othaganont P, Assadian F and Marco J. Battery Electric Vehicle Powertrain Simulation to Optimise Range and Performance'. In: Proc Int. Conf. on Powertrain Modelling and Control 2012. 


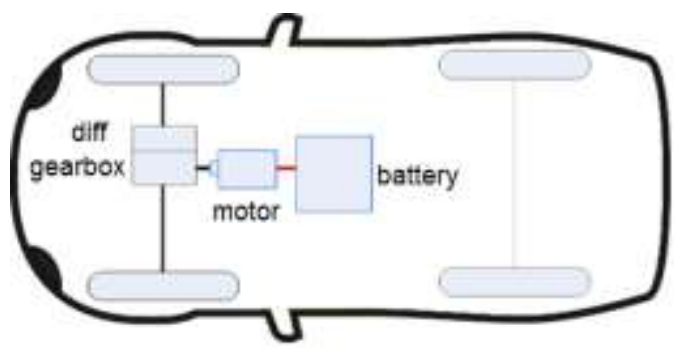

(a) single motor single axle (SM-SA)

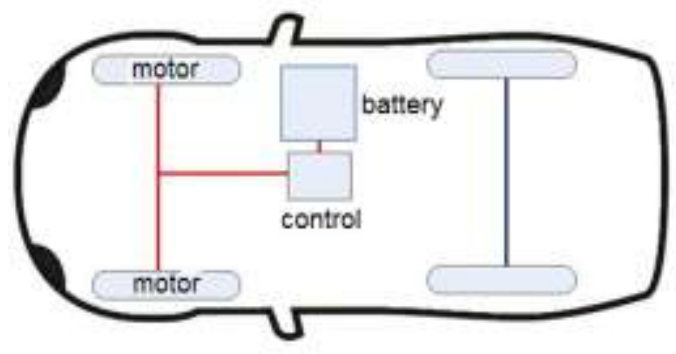

(c) in-wheel motor single axle (IWM-SA)

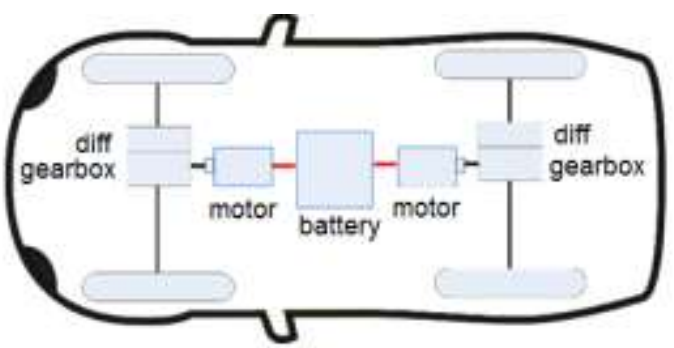

(b) double motor double axle (DM-DA)

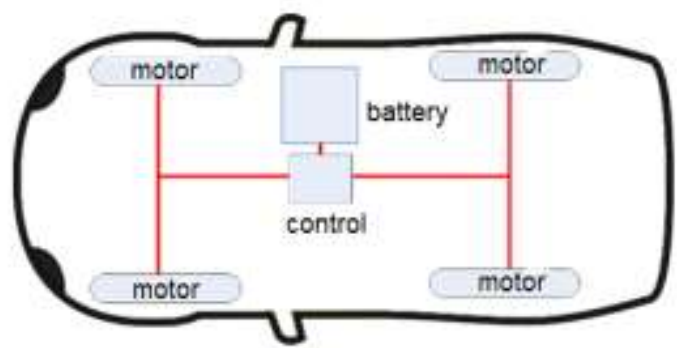

(d) in-wheel motor double axle (IWM-DA)

Fig. 1: Battery electric vehicle powertrain topologies considered in this study.

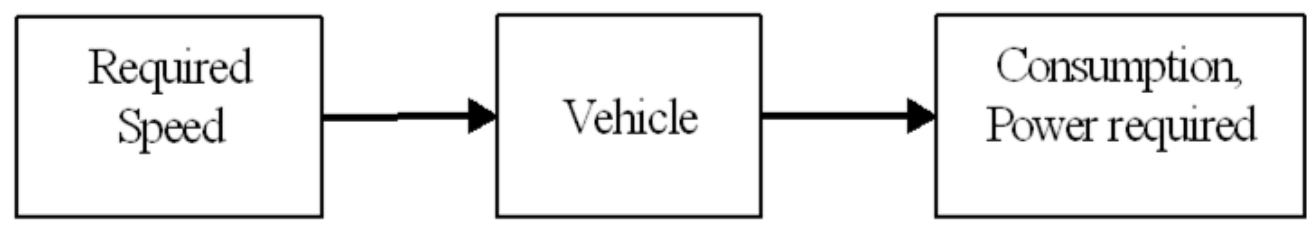

Fig. 2: Backward-facing model of vehicle showing trajectory as input. 


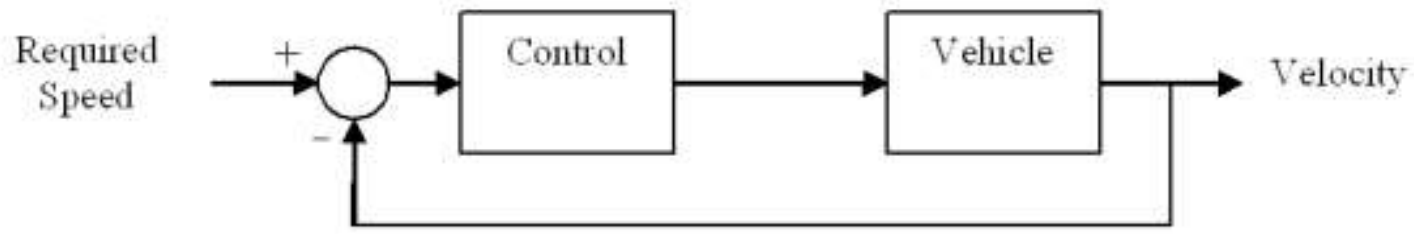

Fig. 3: Forward-facing model of vehicle showing driver feedback loop.

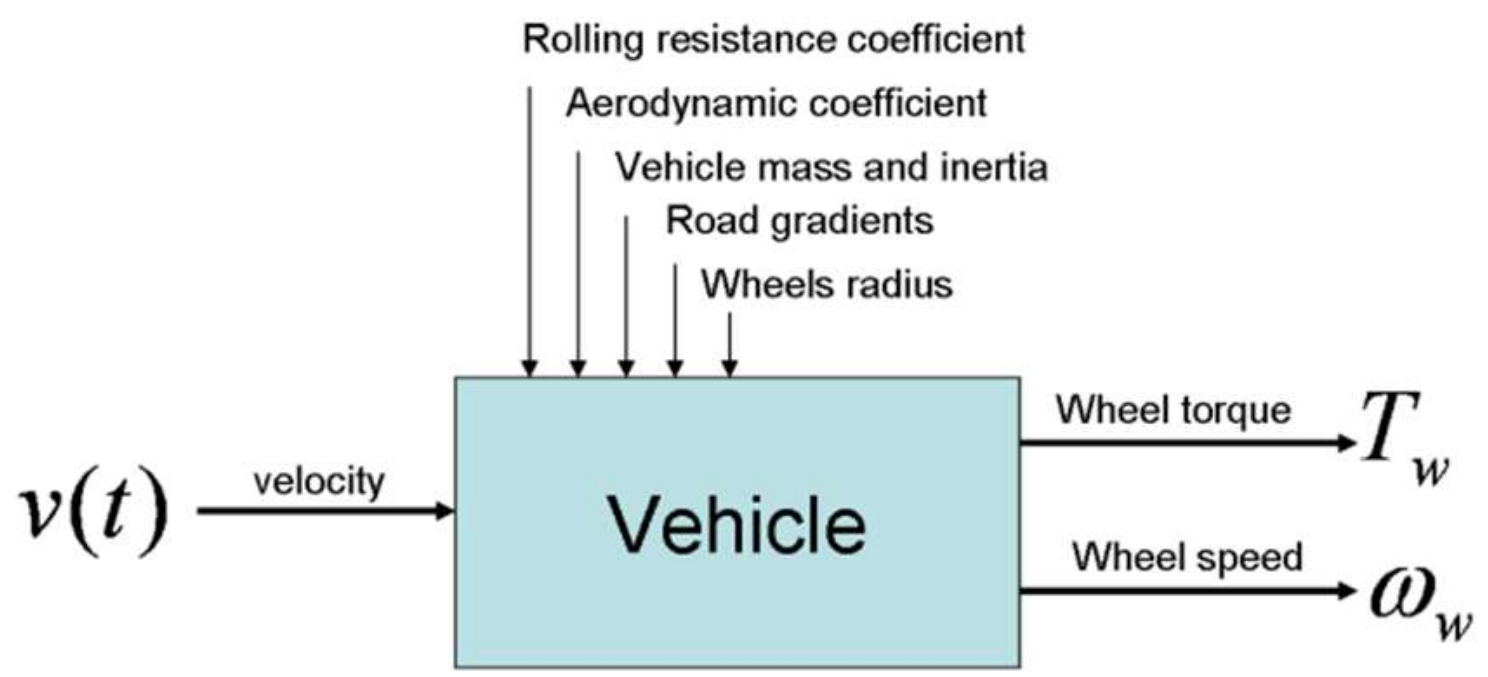

Fig. 4: Inputs and outputs of backward-facing simulation of the vehicle. 


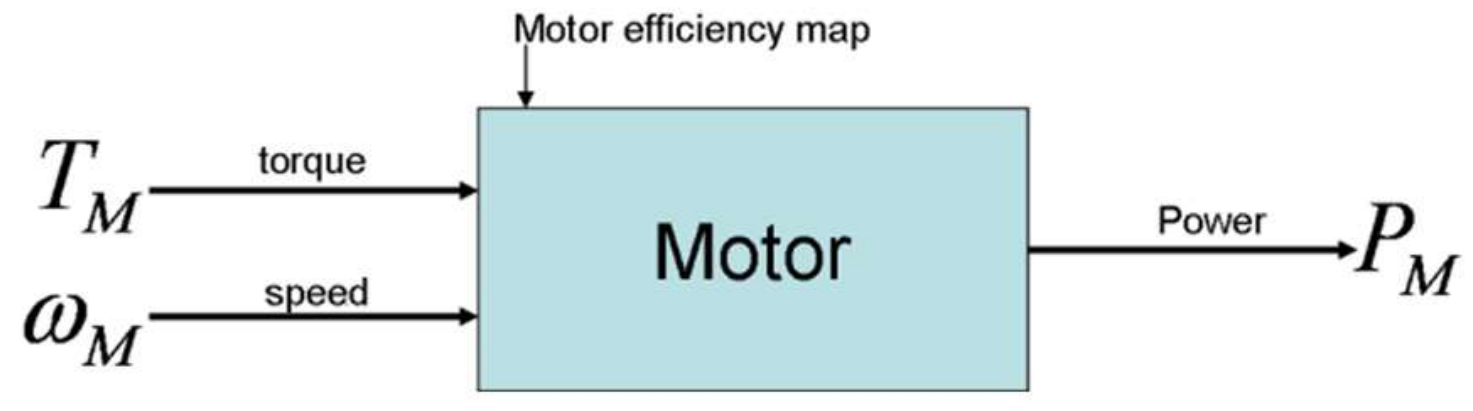

Fig. 5: Inputs and outputs of backward-facing simulation of motor/machine.

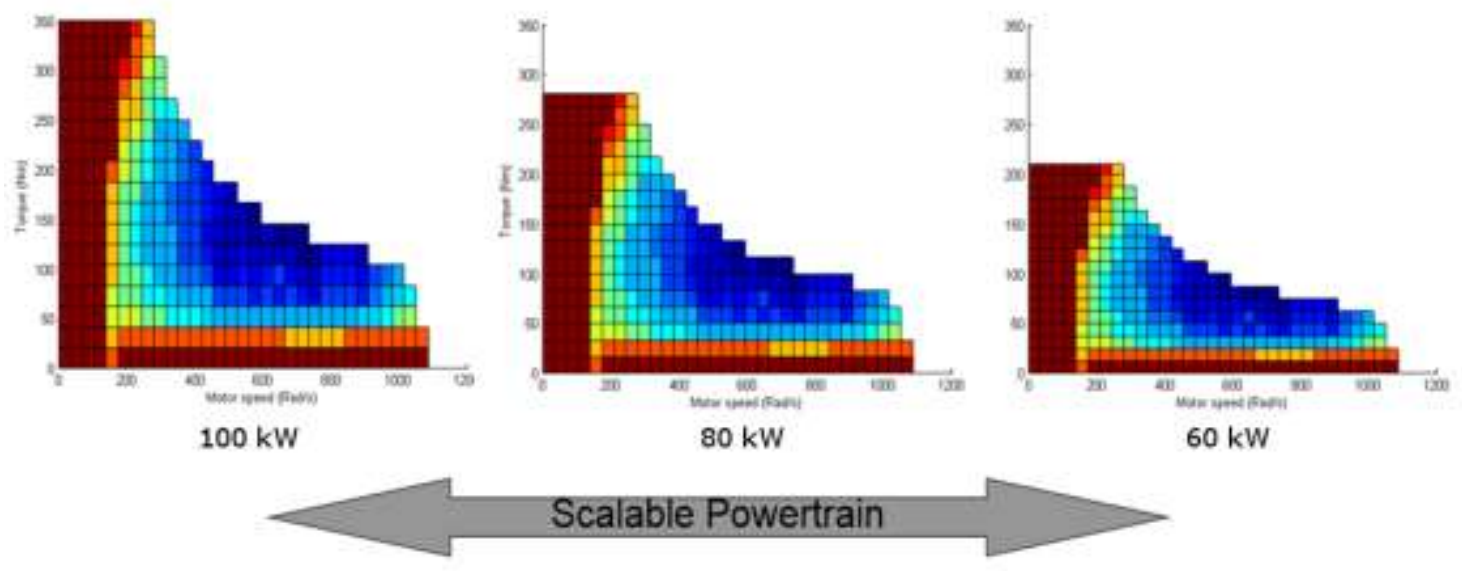

Fig. 6: Scalable motor map for permanent magnet synchronous motor. 


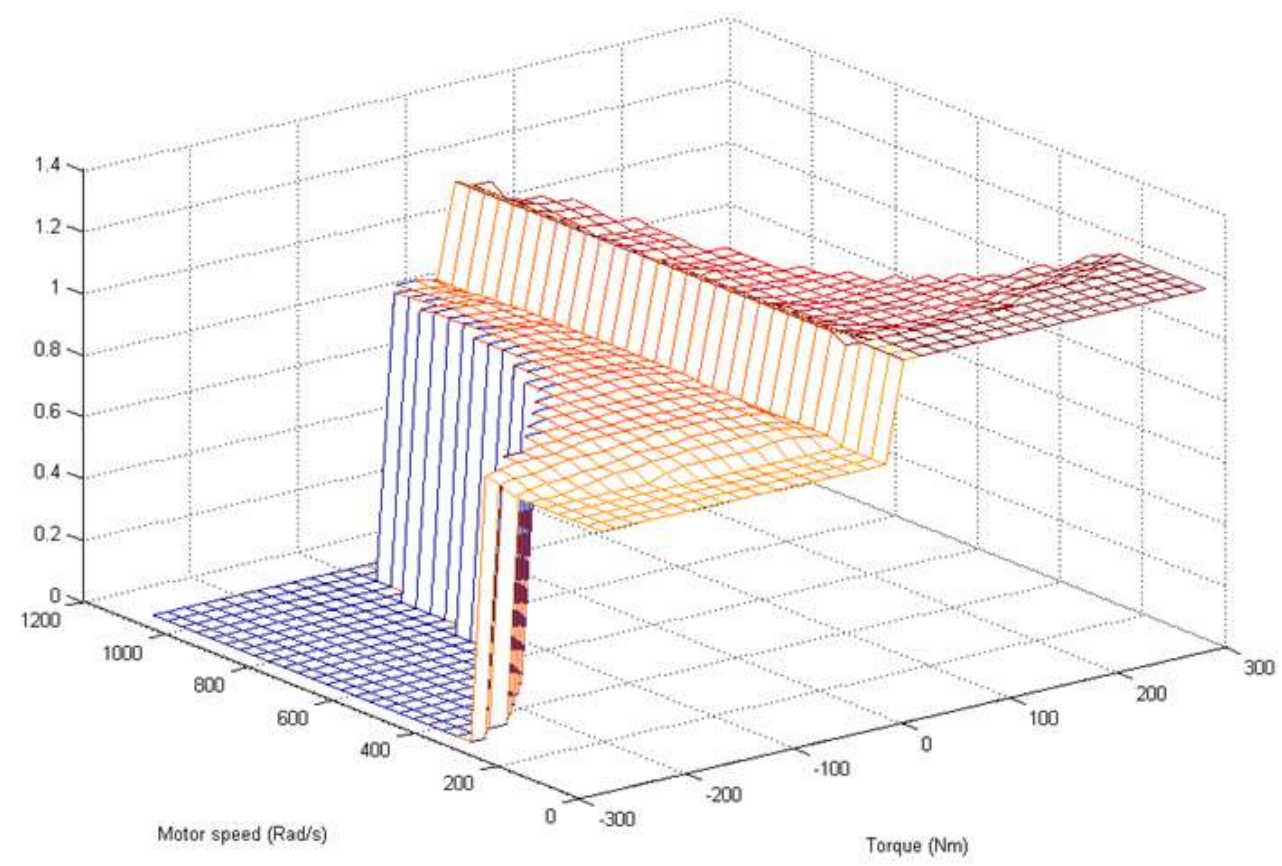

Fig. 7: Motor efficiency map (implemented in model lookup table). 


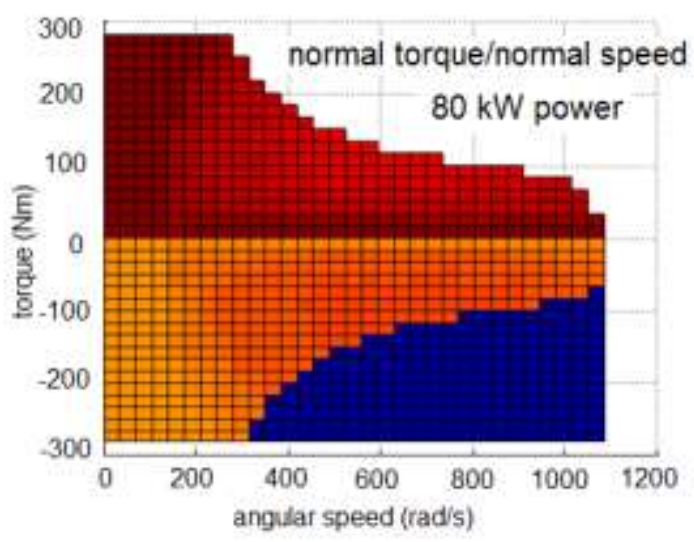

(a) original motor map for conventional motors

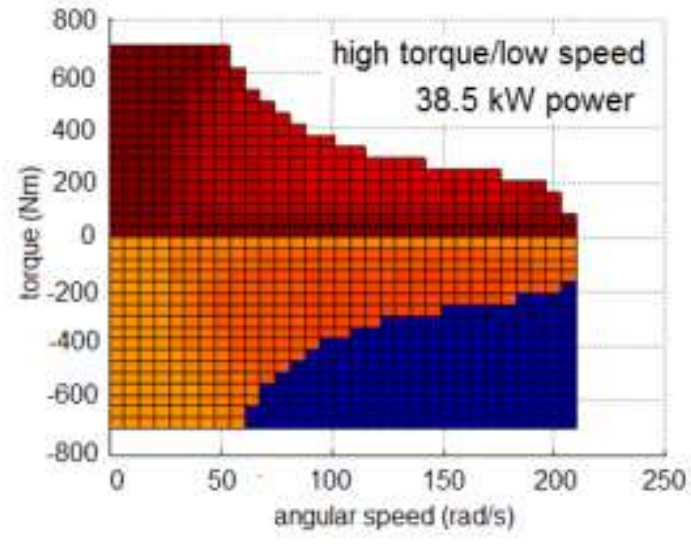

(b) modified motor map

Fig. 8: Modified motor map assumed for in-wheel vehicles.

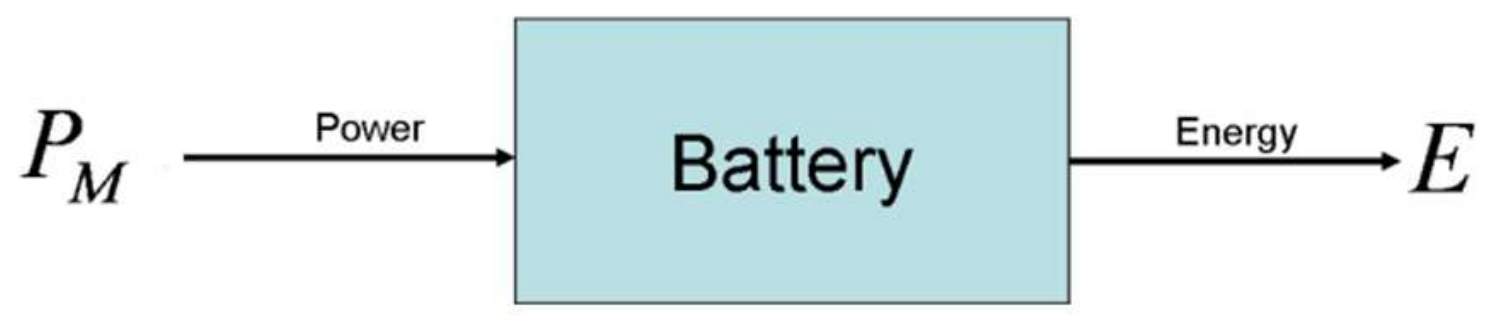

Fig.9: Input and output of backward-facing simulation of battery. 


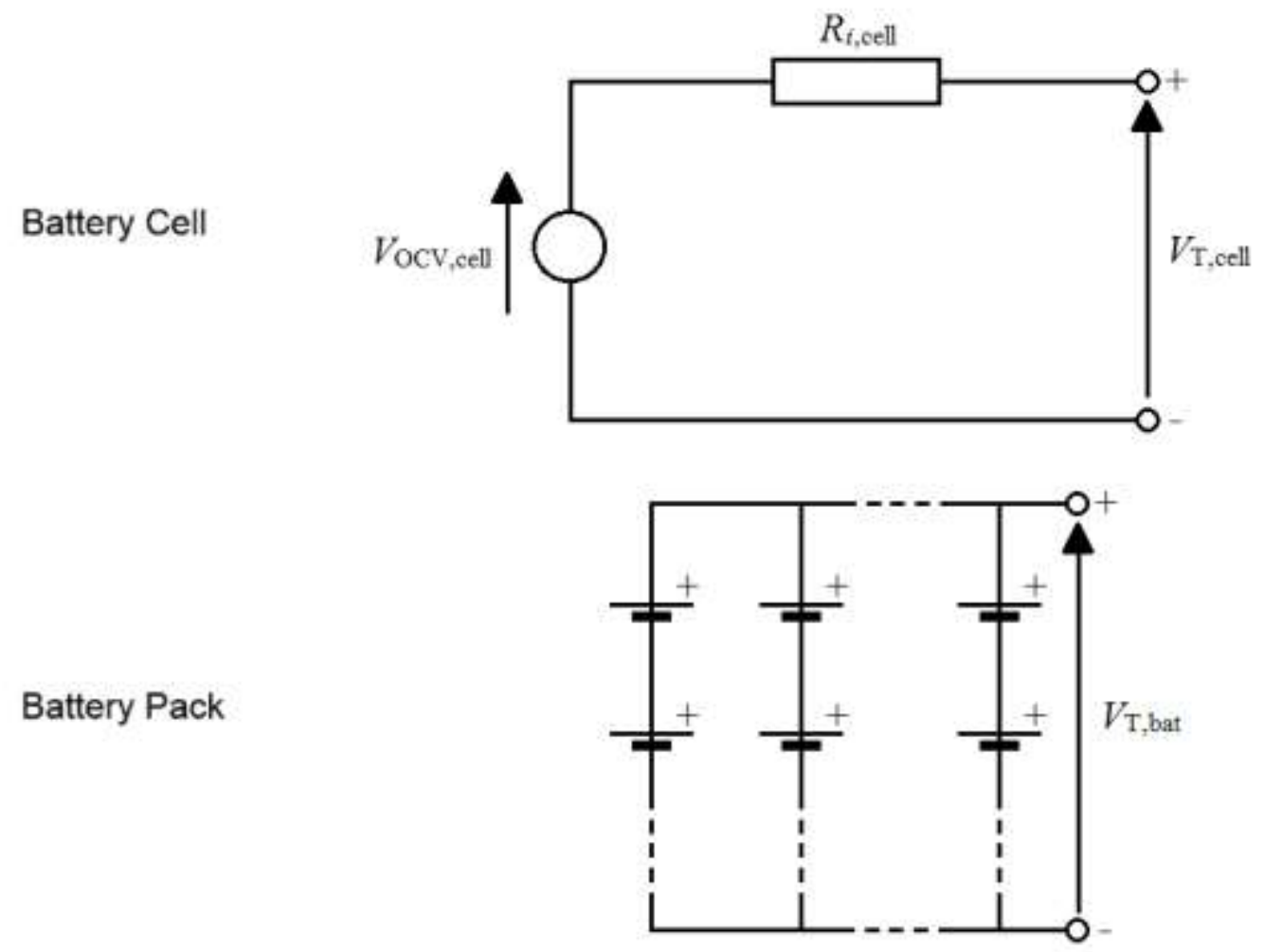

Fig. 10: Cell and battery pack model for electric vehicle. 


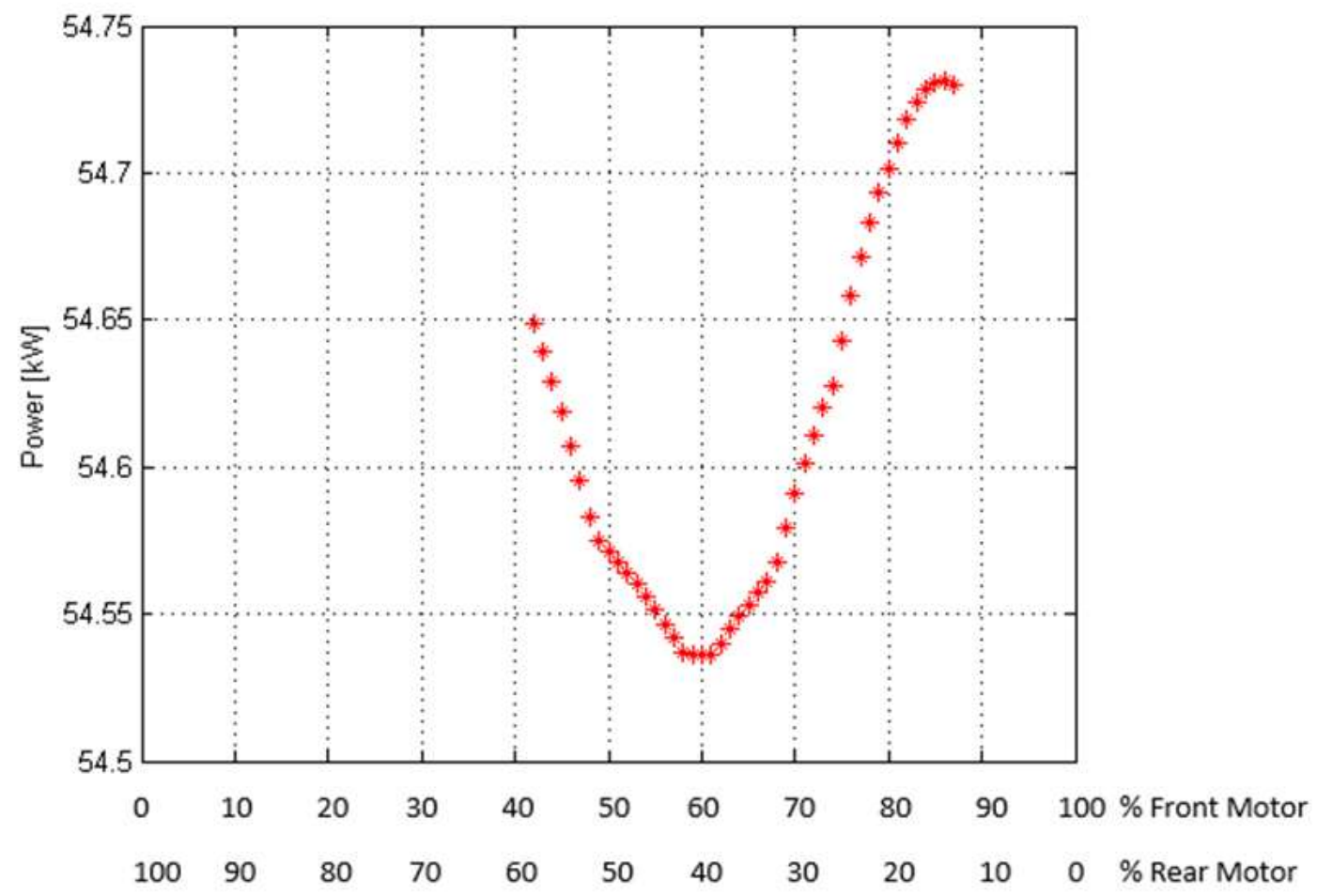

Fig. 11: Relationship of power requirement to torque split. 

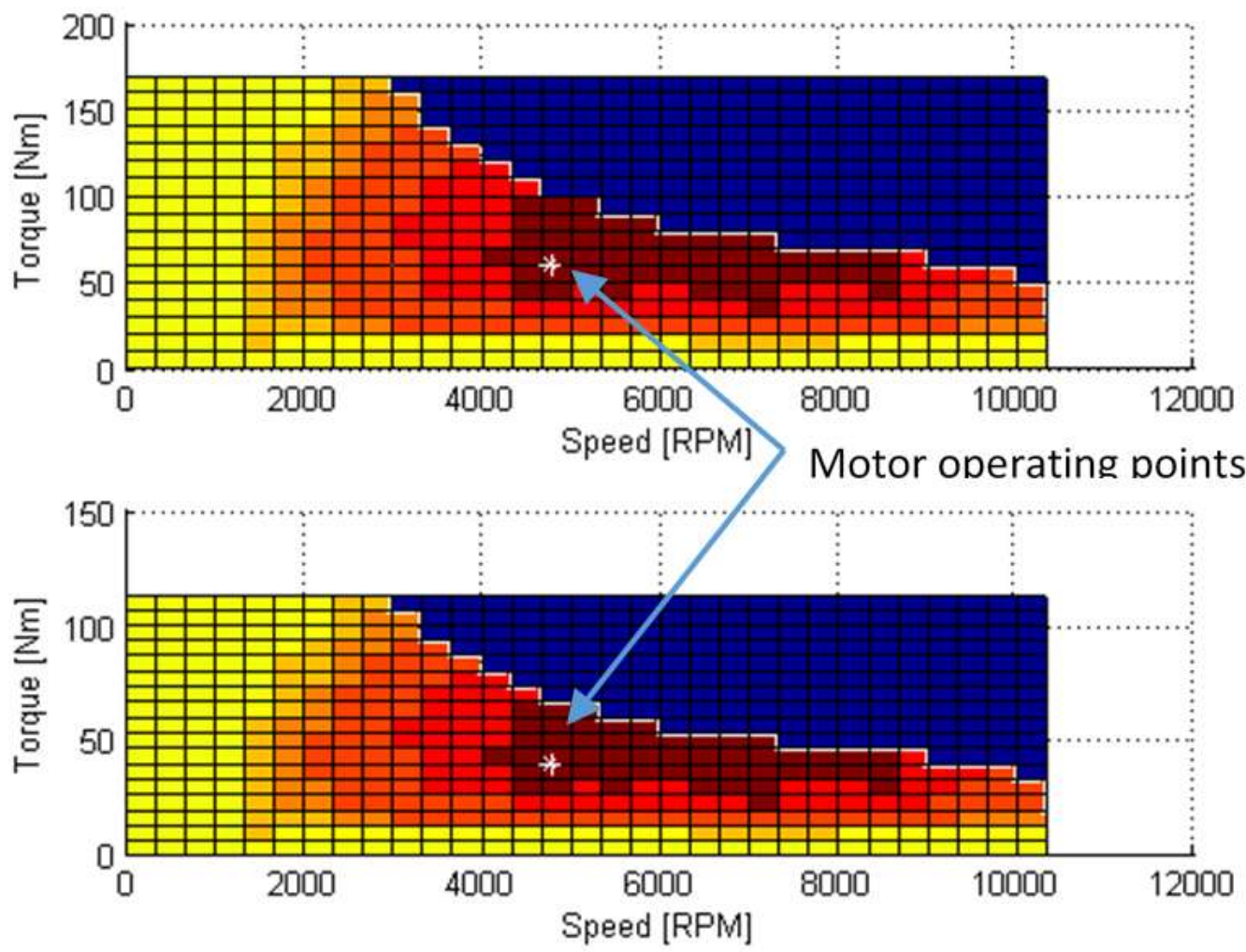

Fig. 12: Power consumption for two motors with torque splitting. 


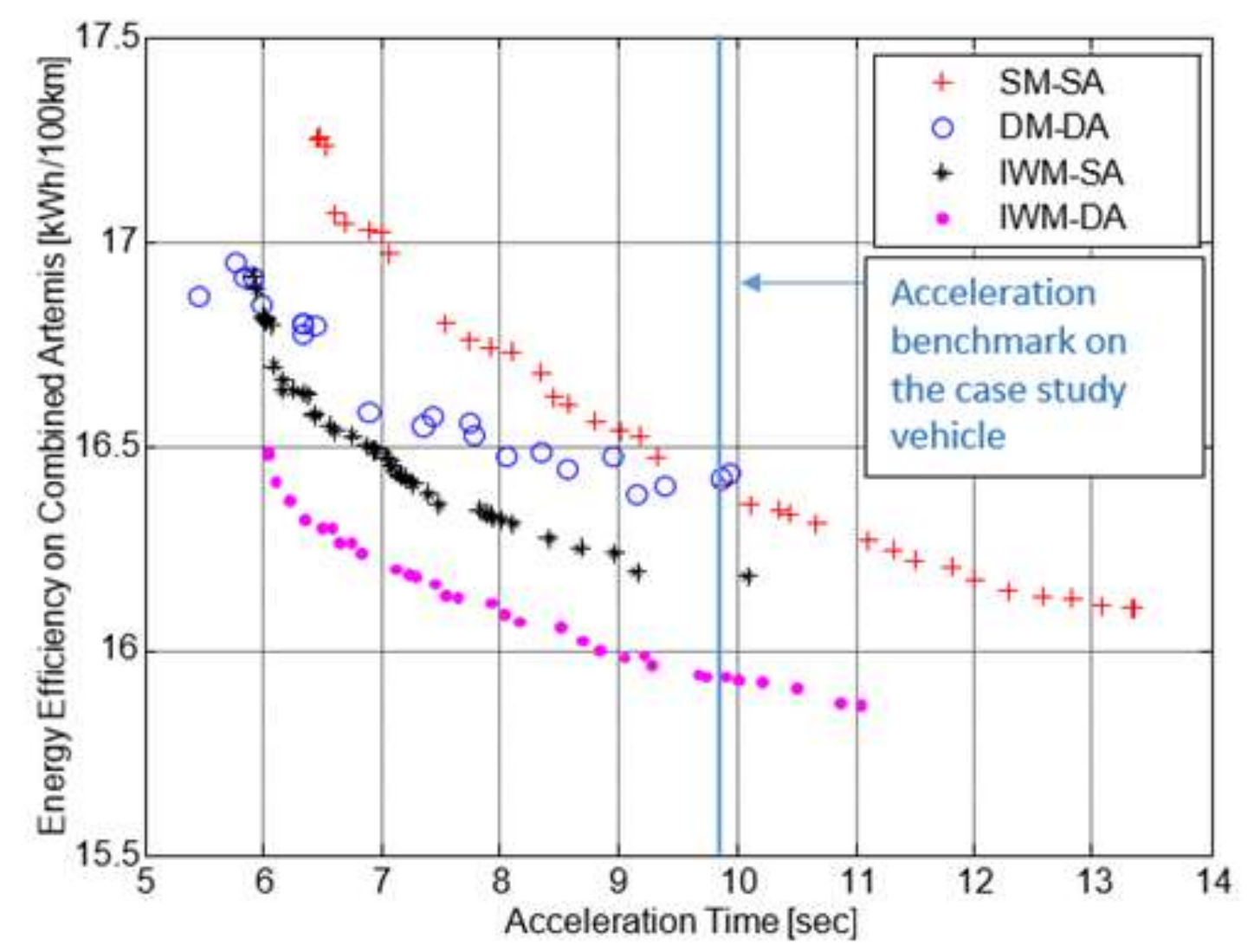

Fig. 13: Pareto front of acceleration time and energy consumption. 


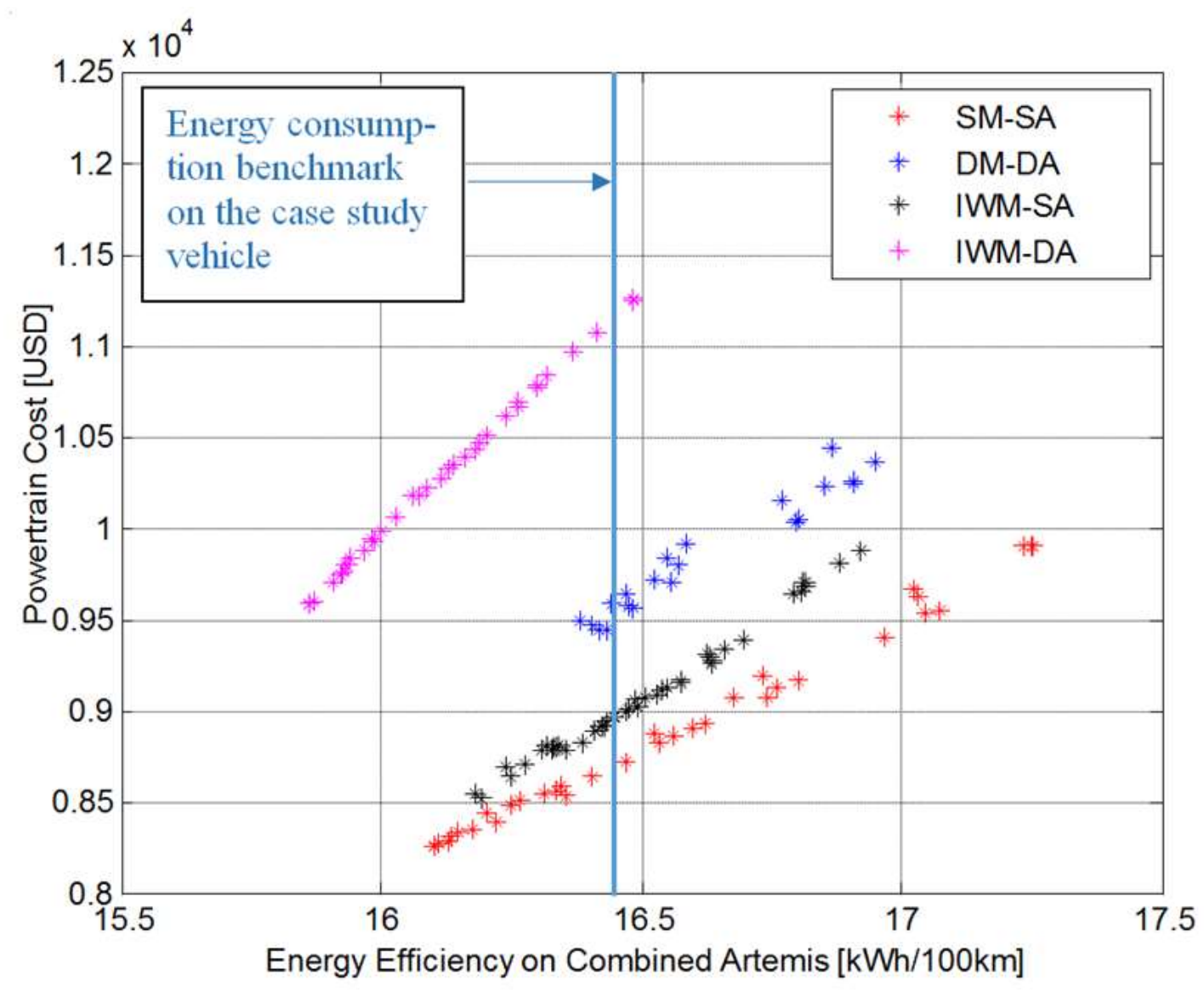

Fig. 14: Pareto front of energy consumption and powertrain cost. 


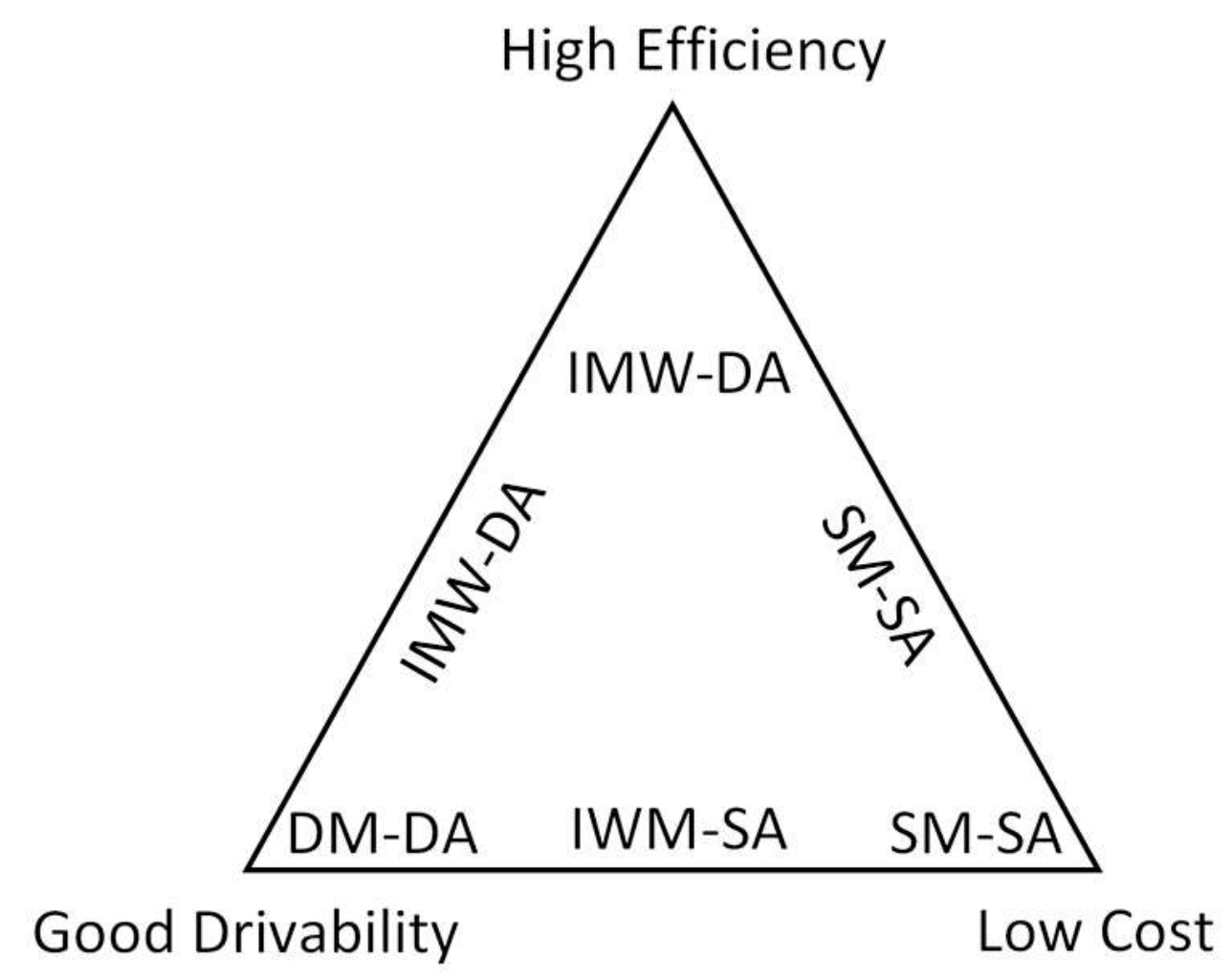

Fig. 15: Trade-offs between different topologies and objective functions. 


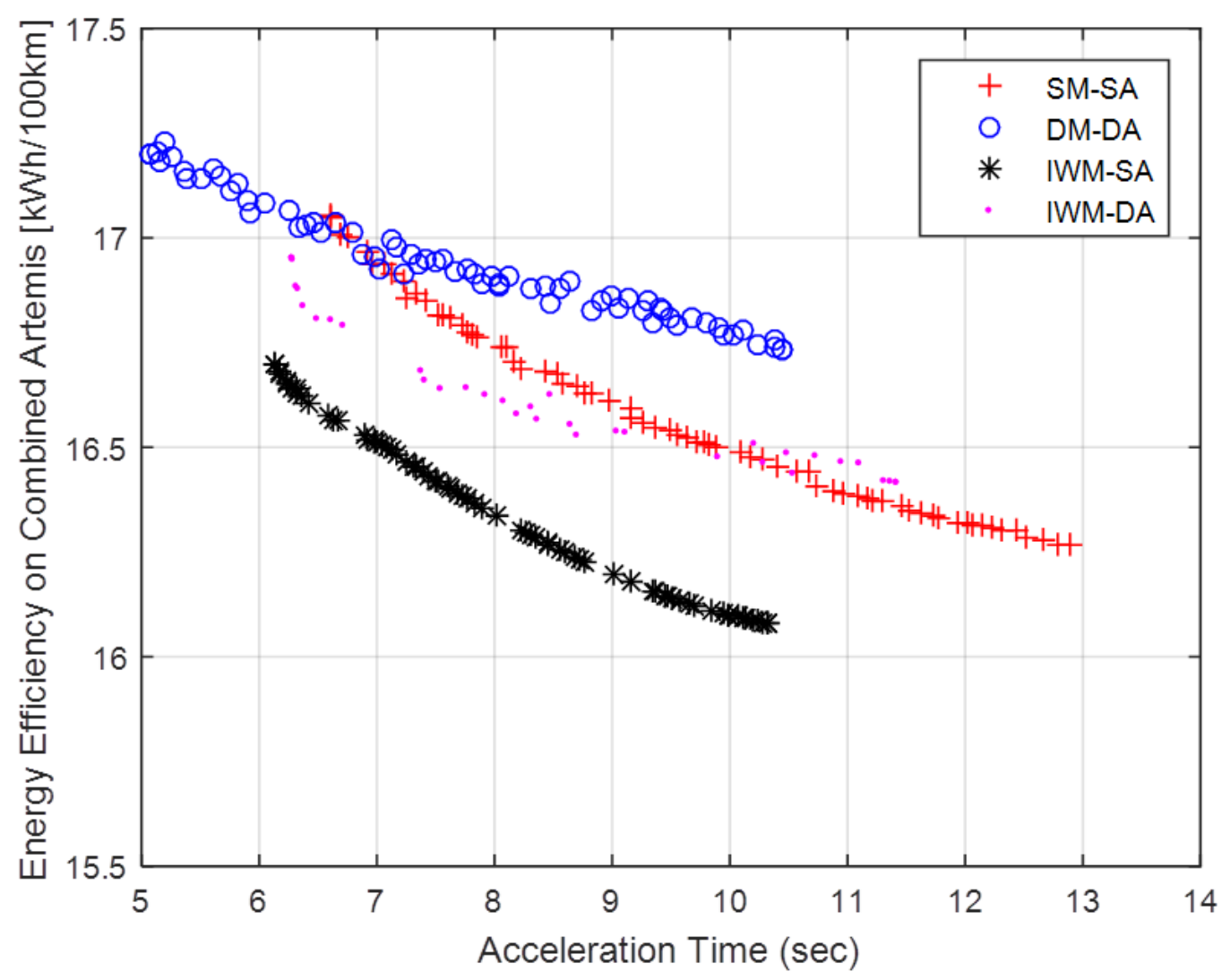

Fig. 16: Pareto front of acceleration time and energy consumption with full payload assumed in optimization. 


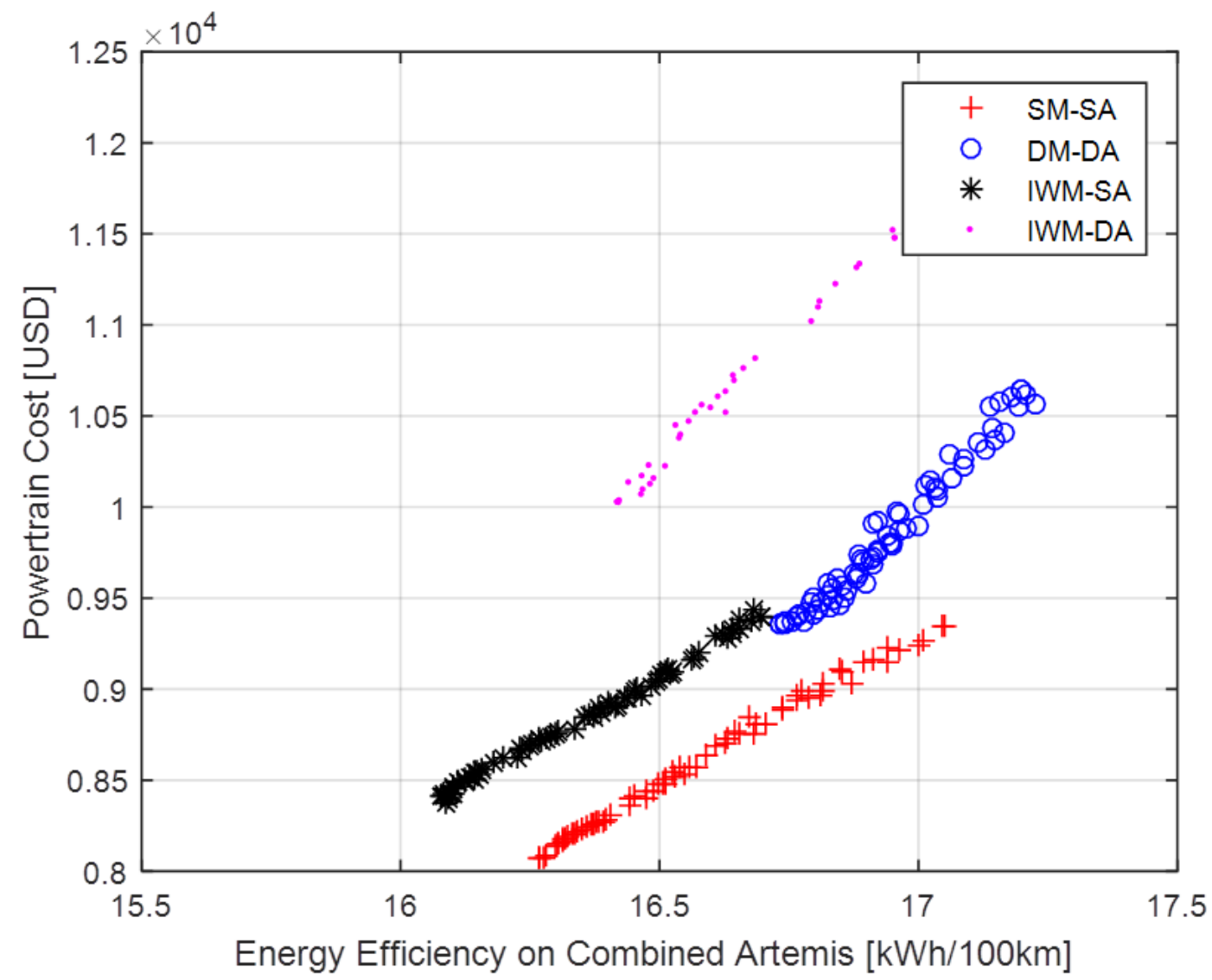

Fig. 17: Pareto front of energy consumption and powertrain cost with full payload assumed in optimization. 
Table 1: Assumed motor masses for each topology.

\begin{tabular}{lcc}
\hline Topology & $\begin{array}{c}\text { Assumed masses of electric machines }(\mathrm{kg}) \\
\text { front }\end{array}$ \\
SM-SA & $0.532 \times P_{\text {motor, } \mathrm{kW}}+21.6$ & no motor \\
& & \\
DM-DA & $0.532 \times P_{\text {motor, } \mathrm{kW}}+21.6$ & $0.532 \times P_{\text {motor, } \mathrm{kW}}+21.6$ \\
& $\begin{array}{c}\left(0.532 \times P_{\text {motor, } \mathrm{kW}}\right. \\
+21.6) \times 2\end{array}$ \\
IWM-SA & no motor \\
& $\begin{array}{c}\left(0.532 \times P_{\text {motor, } \mathrm{kW}}\right. \\
+21.6) \times 2\end{array}$ & $\begin{array}{c}\left(0.532 \times P_{\text {motor,kW }}+21.6\right) \\
\text { IWM-DA }\end{array}$ \\
\hline
\end{tabular}

Table 2: Assumed transmission masses for each topology.

\begin{tabular}{ll}
\hline Topology & Assumptions made regarding powertrain component mass \\
\hline SM-SA & Default, unchanged from case-study vehicle \\
DM-DA & Front axle as SM-SA, additional $30 \mathrm{~kg}$ added for rear axle \\
IWM-SA & Reduction of $25 \%$ compared to SM-SA \\
IWM-DA & Reduction of $25 \%$ compared to SM-SA \\
\hline
\end{tabular}


Table 3: Assumed costs of powertrain components for each topology.

\begin{tabular}{|c|c|c|c|}
\hline \multirow{2}{*}{ Topology } & \multicolumn{3}{|c|}{ Assumed cost of motors and transmission (USD) } \\
\hline & front motor(s) & rear motor(s) & transmission \\
\hline SM-SA & $16 \times P_{\text {motor }, \mathrm{kW}}+385$ & no motor & as case study \\
\hline DM-DA & $16 \times P_{\text {motor }, \mathrm{kW}}+385$ & $16 \times P_{\text {motor }, \mathrm{kW}}+385$ & $\begin{array}{l}\text { second gearbox } \\
+5 \%\end{array}$ \\
\hline IWM-SA & $\begin{array}{c}\left(16 \times P_{\text {motor }, \mathrm{kW}}+385\right) \\
\times 2\end{array}$ & no motor & as case study \\
\hline IWM-DA & $\begin{array}{c}\left(16 \times P_{\text {motor }, \mathrm{kW}}+385\right) \\
\times 2\end{array}$ & $\begin{array}{c}\left(16 \times P_{\text {motor }, \mathrm{kW}}+385\right) \\
\times 2\end{array}$ & as case study \\
\hline
\end{tabular}

Table 4: Masses of powertrain components for each topology prior to any optimization, assuming $80 \mathrm{~kW}$ total motor power.

\begin{tabular}{|c|c|c|c|c|}
\hline Topology & Front motor & Rear motor & $\begin{array}{c}\text { Transmission } \\
\text { mass }\end{array}$ & $\begin{array}{c}\text { Difference } \\
\text { from LEAF } \\
(\mathrm{kg})\end{array}$ \\
\hline SM-SA & $\begin{array}{c}\text { one motor @ } \\
80 \mathrm{~kW} / 64.16 \mathrm{~kg}\end{array}$ & no motor & as case study & \pm 0.0 \\
\hline DM-DA & $\begin{array}{c}\text { one motor @ } \\
40 \mathrm{~kW} / 42.88 \mathrm{~kg}\end{array}$ & $\begin{array}{c}\text { one motor @ } \\
40 \mathrm{~kW} / 42.88 \text { kg }\end{array}$ & $\begin{array}{c}30 \text { kg added } \\
\text { (rear gearbox) }\end{array}$ & +51.6 \\
\hline IWM-SA & $\begin{array}{c}\text { two motors each @ } \\
40 \text { kW / } 42.88 \text { kg }\end{array}$ & no motor & $25 \%$ reduction & +0.16 \\
\hline IWM-DA & $\begin{array}{c}\text { two motors each @ } \\
20 \mathrm{~kW} / 32.24 \mathrm{~kg}\end{array}$ & $\begin{array}{c}\text { two motors each @ } \\
20 \mathrm{~kW} / 32.24 \mathrm{~kg}\end{array}$ & $25 \%$ reduction & +32.6 \\
\hline
\end{tabular}


Table 5: Energy efficiencies for each topology prior to optimization, assuming $80 \mathrm{~kW}$ total motor power.

\begin{tabular}{lcccc}
\hline Topology & $\begin{array}{c}\text { Vehicle mass } \\
(\mathbf{k g})\end{array}$ & $\begin{array}{c}\text { Acceleration } \\
\text { time (s) }\end{array}$ & $\begin{array}{c}\text { Cost } \\
\text { (USD) }\end{array}$ & $\begin{array}{c}\text { Energy cons. } \\
\text { (kWh/100km) }\end{array}$ \\
\hline SM-SA & 1520 & 9.9 & 8,900 & 16.5 \\
DM-DA & 1570 & 10.5 & 9,300 & 16.6 \\
IWM-SA & 1520 & 11.2 & 9,300 & 16.0 \\
& & & & 16.1 \\
IWM-DA & 1550 & 11.5 & 10,100 & \\
\hline
\end{tabular}

Table 6: Energy consumption for each topology after optimization, subject to a constraint of meeting a specified driveability 'benchmark' (0-100 km/h in $9.9 \mathrm{~s})$.

\begin{tabular}{lccccc}
\hline Topology & $\begin{array}{c}\text { motor size } \\
(\mathbf{k W}) \\
\text { front / rear }\end{array}$ & $\begin{array}{c}\text { transmission ra- } \\
\text { tio } \\
\text { front/rear }\end{array}$ & $\begin{array}{c}\text { battery } \\
\text { size } \\
\mathbf{( k W h})\end{array}$ & $\begin{array}{c}\text { energy con- } \\
\text { sumption } \\
(\mathbf{k W h} / \mathbf{1 0 0 k m})\end{array}$ & $\begin{array}{c}\text { powertrain } \\
\text { cost } \\
(\mathbf{U S D})\end{array}$ \\
\hline Case study & $80 /-$ & $7.9 /-$ & 24.0 & $16.5( \pm 0.0 \%)$ & 8,900 \\
SM-SA & $80 /-$ & $8.1 /-$ & 23.0 & $16.4(-0.5 \%)$ & 8,600 \\
DM-DA & $42 / 46$ & $6.56 / 6.29$ & 24.0 & $16.4(-0.3 \%)$ & 9,400 \\
IWM-SA & $2 \times 43 /-$ & direct drive & 21.1 & $16.2(-1.8 \%)$ & 8,500 \\
IWM-DA & $2 \times 29 / 2 \times 17$ & direct drive & 22.3 & $16.0(-3.3 \%)$ & 9,800 \\
\hline
\end{tabular}


Table 7: Powertrain cost for each topology after optimization, subject to a constraint of meeting a specified energy consumption 'benchmark' (16.45 kWh/100 km).

\begin{tabular}{lcccccc}
\hline Topology & $\begin{array}{c}\text { motor size } \\
(\mathbf{k W}) \\
\text { front } / \text { rear }\end{array}$ & $\begin{array}{c}\text { Transmission } \\
\text { ratio } \\
\text { front / rear }\end{array}$ & $\begin{array}{c}\text { Battery size } \\
(\mathbf{k W h})\end{array}$ & $\begin{array}{c}\text { Powertrain cost } \\
(\mathbf{U S D})\end{array}$ & $\begin{array}{c}\mathbf{0}-\mathbf{1 0 0} \\
\mathbf{k m} / \mathbf{h} \\
(\mathbf{s})\end{array}$ \\
\hline Case study & $80 /-$ & $7.9 /-$ & 24.0 & $8,900 \quad( \pm 0.0 \%)$ & 9.9 \\
SM-SA & $84 /-$ & $8.0 /-$ & 23.0 & $8,700 \quad(-2.4 \%)$ & 9.3 \\
DM-DA & $60 / 40$ & $8.0 / 8.0$ & 24.0 & $9,600 \quad(+8.0 \%)$ & 8.0 \\
IWM-SA & $2 \times 62 /-$ & direct drive & 20.5 & $9,000 \quad(+0.9 \%)$ & 7.0 \\
IWM-DA & $2 \times 65 / 2 \times 20$ & direct drive & 23.3 & $11,300 \quad(+26.0 \%)$ & 6.0
\end{tabular}


2016-10-06

\section{Multi-objective optimisation for battery electric vehicle powertrain topologies}

\section{Othaganont, Pongpun}

Proceedings of the Institution of Mechanical Engineers, Part D: Journal of Automobile Engineering

Othaganont P, Assadian F and Auger DJ., Multi-objective optimisation for battery electric vehicle powertrain topologies. Proceedings of the Institution of Mechanical Engineers, Part D: Journal of Automobile Engineering, Volume 231, Issue 8, pp. 1046-1065 https://doi.org/10.1177/0954407016671275

Downloaded from Cranfield Library Services E-Repository 